\title{
O Método de Dobramento Recursivo para Imersão em Hipercubos e suas Aplicações
}

Carla Yayoi Takemoto

\author{
DISSERTAÇÃO APRESENTADA \\ $\mathrm{AO}$ \\ INSTITUTO DE MATEMÁTICA E ESTATÍSTICA \\ DA \\ UNIVERSIDADE DE SÃO PAULO \\ PARA \\ OBTENÇÃO DO GRAL: DE MESTRE \\ EM \\ MATEMÁTICA APLICADA
}

\section{Área de Concentração: Ciência da Computação Orientador: Prof. Dr. Siang Wun Song}

São Paulo, agosto de 1998

Durante a elaboração deste trabalho o autor recebeu apoio financeiro do CNPq e da FAPESP 


\section{O Método de Dobramento Recursivo para Imersão em Hipercubos e suas Aplicações}

Este exemplar corresponde à redação final da dissertação devidamente corrigida e defendida por Carla Yayoi Takemoto e aprovada pela comissão julgadora.

São Paulo, 16 de outubro de 1998.

Banca examinadora:

- Prof. Dr. Siang Wun Song (orientador) - IME/USP

- Prof. Dr. Carlos Eduardo Ferreira - IME/USP

- Prof. Dr. Marcos Nereu Arenales - ICMC/USP 
Aos meus pais,

Izabel e Akira. 


\section{Agradecimentos}

Ao Prof. Siang, pela paciência e dedicação na orientação e por todos os ensinamentos.

Ao Prof. Carlinhos, pelas dicas dadas no início do programa como orientador de programa.

À minha família, em especial, aos meus pais, pelo amor e incentivo incondicionais.

Aos amigos do IME, Mary, Cao, Flávio, Edson, Marco Aurélio, Maurício, que fizeram este mestrado ser mais ameno.

Às minhas primas, Cenyra e Márcia, pelo companheirismo.

À Marcinha, pela amizade incondicional.

À FAPESP e CNPq, pelo apoio financeiro. 


\section{Resumo}

A imersào de uma rede de interconexão em outra é uma questão muito importante no desenvolvimento e na análise de algoritmos paralelos. Através destas imersões, os algoritmos originalmente desenvolvidos para uma determinada arquitetura podem ser mapeados para uma outra arquitetura.

Os resultados de imersão de um $m$-cubo $r$-ário em um hipercubo já são conhecidos na literatura. Neste trabalho, apresentaremos o método do código de Gray de Saad e Schultz e o método do dobramento recursivo proposto por Song e Hamdi para este tipo de imersão. Este segundo método possui uma propriedade que possibilita a identificação imediata de todos os subcubos menores de um $m$-cubo $r$-ário.

Nas publicações anteriores sobre o método do dobramento recursivo, entretanto, não há exemplos que ilustrem a aplicabilidade e utilidade desta propriedade. Mostramos neste trabalho que o método do dobramento recursivo pode ser útil para uma classe de problemas matriciais resolvidos com algoritmos do tipo divisão-e-conquista. Mais especificamente, apresentaremos três algoritmos recursivos, para os problemas de obtenção da transposta de uma matriz, multiplicação de matrizes e ordenação por intercalação Par-Ímpar, propostos para um $m$-cubo $r$-ário que necessitem de todos os subcubos menores. 


\begin{abstract}
The embedding of one interconnection network in another is an important question in the design and analysis of parallel algorithms. Through an embedding, algorithms originally designed for a certain architecture can be mapped to another architecture.

Results of embedding of an $r$-ary $m$-cube into the hypercube are already known in the literature. In this work, we present the Gray code method of Saad and Schultz and the recursive folding method proposed by Song and Hamdi for this type of embedding. This second method possesses a property that enables the immediate identification of all the smaller subcubes of an $r$-ary $m$-cube.

In previous publication about the recursive folding method, however, there are no examples that illustrate the applicability and utility of this property. In this work we show that the recursive folding method can be useful in a class of problems using matrices solved by recursive divide-and-conquer algorithms. More especifically, we present three recursive algorithms for the problems of matrix transpose, matrix multiplication and Odd-Even merge sorting, proposed for an $r$-ary $m$-cube and that require all the smaller subcubes.
\end{abstract}




\section{Conteúdo}

1 Introdução 1

2 Redes de interconexão 4

2.1 Definições básicas . . . . . . . . . . . . . . . . . . . 4

2.2 Exemplos de redes de interconexão . . . . . . . . . . . . . . . . . 5

2.2 .1 Hipercubos . . . . . . . . . . . . . . . . . 5

2.2 .2 Árvores binárias . . . . . . . . . . . . . . 6

2.2 .3 Grades . . . . . . . . . . . . . . . . 7

2.2 .4 Grades toroidais . . . . . . . . . . . . . . . 7

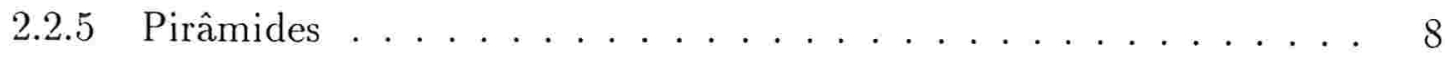

$2.2 .6 \quad \mathrm{X}$-árvores $\ldots \ldots \ldots \ldots \ldots \ldots$

2.2 .7 Malhas de árvores . . . . . . . . . . . . . . . . . . . 10

2.2 .8 Borboletas . . . . . . . . . . . . . . . . 10

2.2.9 Ciclos conectados em cubo . . . . . . . . . . . . . . 11

3 Imersão de grafos $\quad 13$

3.1 Definição . . . . . . . . . . . . . . . . . . . . . 13

3.2 Imersão em hipercubos . . . . . . . . . . . . . . . . . . . 14

3.2 .1 Árvores binárias . . . . . . . . . . . . . . . . 14

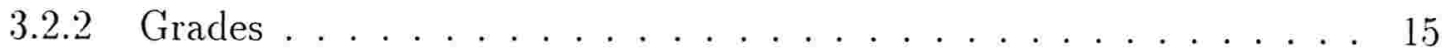

3.2 .3 Pirâmides . . . . . . . . . . . . . . . . 15

3.2 .4 X-árvores . . . . . . . . . . . . . . . . . 16 
3.2 .5 Malhas de árvores . . . . . . . . . . . . . 16

3.2 .6 Borboletas e ciclos conectados em cubo . . . . . . . . . . . . 16

3.3 Imersão do $m$-cubo $r$-ário no $n$-cubo binário . . . . . . . . . . . . 16

3.3 .1 Método do dobramento recursivo . . . . . . . . . . . . . 16

3.3 .2 Método do código de Gray . . . . . . . . . . . . . . 26

3.4 Diferença entre os dois métodos . . . . . . . . . . . . . . . . . 28

4 Utilidade do método do dobramento recursivo 30

4.1 Utilização da propriedade . . . . . . . . . . . . . . . . . 30

4.1 .1 Transposição de matriz . . . . . . . . . . . . . . . . . . 31

4.1 .2 Multiplicação de matrizes . . . . . . . . . . . . . . . . 34

4.1 .3 Ordenação por intercalação Par-Ímpar . . . . . . . . . . . . . 38

5 Conclusão $\quad 49$

A Tabelas de parâmetros $\quad 51$

$\begin{array}{ll}\text { Bibliografia } & 54\end{array}$ 


\section{Capítulo 1}

\section{Introdução}

Pesquisas em computação paralela dentro da Ciência da Computação vêm adquirindo importância cada vez maior nestas últimas décadas. Os principais motivos pelos quais isto esteja ocorrendo são: a dificuldade em aumentar o desempenho dos computadores seqüenciais e a disponibilidade de microprocessadores baratos fabricados em massa, que permite conectar um grande número destes componentes em um computador paralelo de maneira econômica. Assim, várias máquinas paralelas estão ganhando prestígio e vêm sendo muito utilizadas atualmente.

A computação paralela caracteriza-se pela presença de vários processadores trabalhando simultaneamente para resolver um mesmo problema. Neste trabalho, consideramos máquinas paralelas de memória distribuída. Os processadores estão ligados entre si segundo uma topologia através de uma rede de interconexão. Essa rede pode ser representada por um grafo, onde os vértices são os processadores e as arestas são os canais de comunicação. Desta forma, os processadores comunicam-se entre si através do envio de mensagens por esses canais.

Devido às diversas topologias existentes para interconectar os processadores, um conceito importante é o de imersão (embedding) de um grafo em outro chamado grafo hospedeiro. A imersão nada mais é do que um mapeamento um a um entre os vértices do grafo a ser imerso e os vértices do grafo hospedeiro, que satisfaz a propriedade de que dois vértices adjacentes no grafo imerso estão relacionados a outros dois vértices do grafo hospedeiro que possuam algum caminho entre si. Então, supondo que haja um algoritmo desenvolvido em uma determinada arquitetura e que a topologia desta arquitetura possa ser imersa em uma outra, um algoritmo correspondente na segunda arquitetura pode ser obtido sem grande esforço. Uma imersão pode ser considerada boa, segundo a medida de qualidade chamada dilatação, se cada par de vértices adjacentes do grafo a ser imerso é levado a um par de vértices vizinhos no grafo hospedeiro. 
O hipercubo ( $n$-cubo binário) vem se destacando como uma das mais populares redes de interconexão para máquinas paralelas. Ele é utilizado nas seguintes máquinas: Intel iPSC, NCube e Connection Machine, por exemplo. Esse destaque é devido, entre outras razões. a seu pequeno diâmetro e grau ( $\log n$. onde $n$ é o seu número de nós), a facilidade de roteamento e a sua capacidade de simular eficientemente outras arquiteturas paralelas. Além disso, o hipercubo pode ser totalmente dividido em subcubos permitindo a implementação de algoritmos do tipo divisão-e-conquista.

Na literatura, há uma série de resultados conhecidos sobre imersões em algumas das topologias mais comuns. Utilizando medidas de qualidade de imersão, como dilatação, expansão e congestionamento, mostramos como é possível imergir no hipercubo grafos como árvores binárias, grades, pirâmides, entre outros.

Neste trabalho, estamos interessados na imersão de um $m$-cubo $r$-ário no hipercubo. Sabemos que o $n$-cubo binário contém qualquer $m$-cubo $r$-ário, com o mesmo número de nós, se $r$ for uma potência de 2 [Cha\$8, CC88, CC93, Lei92, SS88]. Estes métodos de imersão são baseados no código de Gray. Entretanto, utilizaremos aqui uma construção diferente para este tipo de imersão chamada de método do dobramento recursivo proposto por Song e Hamdi [HS96, Son94]. Neste caso, dobramos recursivamente o hipercubo tal que a disposição final contém o $m$-cubo $r$-ário. Esta disposição, chamada de $T(r, m)$, possui a seguinte propriedade: Todos os subcubos, formados pelos nós com os mesmos primeiros $k m$ bits, para $1 \leq k<\log r$, também estão dispostos em $m$-cubos $\left(r / 2^{k}\right)$-ários. O método de imersão do dobramento recursivo possibilita a identificação imediata de todos os subcubos menores de um $m$-cubo $r$-ário. Isto não se verifica no método do código de Gray.

Como nos trabalhos anteriores sobre o método do dobramento recursivo não há exemplos que ilustrem a aplicabilidade e utilidade desta propriedade, apresentaremos nesta dissertação três algoritmos recursivos propostos para um $m$-cubo $r$-ário que necessitem de todos os subcubos menores. Assim, se implementarmos estes algoritmos no hipercubo utilizando a disposição $T(r, m)$ podemos obter de maneira fácil os endereços destes subcubos através da mencionada propriedade.

Esta dissertação está organizada da seguinte maneira.

No capítulo 2, apresentaremos inicialmente definições básicas sobre grafos que serão utilizadas no resto da dissertação. A seguir, exibiremos algumas das principais redes de interconexão para máquinas paralelas, acompanhadas de suas medidas de desempenho, o diâmetro e o grau máximo.

O assunto principal do capítulo 3 é a imersão de grafos. Começamos este capítulo apresentando a definição de imersão de uma rede de interconexão em outra e suas me- 
didas de qualidade, dilatação, expansão e congestionamento. Em seguida, mostraremos resultados conhecidos na literatura para imersões de algumas redes de interconexão em um hipercubo. Ainda neste capítulo, descrevemos os métodos do dobramento recursivo [HS96, Son94] e do código de Gray, proposto por Saad e Schultz [SS88], para imersão de um $m$-cubo $r$-ário no $n$-cubo. Finalizando este capítulo, apontaremos uma diferença entre estes dois métodos.

No capítulo 4, apresentaremos três exemplos de aplicações concretas que podem tirar proveito da propriedade do dobramento recursivo. Os exemplos são três algoritmos recursivos, para os problemas de obtenção da transposta de uma matriz, multiplicação de matrizes e ordenação por intercalação Par-Ímpar, propostos para um $m$-cubo $r$-ário que necessitem de todos os subcubos menores.

Finalmente, no capítulo $\check{\jmath}$ faremos os comentários finais sobre a dissertação.

No apêndice $\mathrm{A}$, apresentaremos duas tabelas. A primeira tabela mostra algumas das principais redes de interconexão e seus parâmetros de desempenho e a segunda tabela apresenta resultados conhecidos de imersões no hipercubo. 


\section{Capítulo 2}

\section{Redes de interconexão}

A computação paralela caracteriza-se pela presença de vários processadores trabalhando simultaneamente para resolver um mesmo problema. Numa máquina paralela de memória distribuída, os processadores estão ligados entre si segundo uma topologia através de uma rede de interconexão. Essa rede pode ser representada por um grafo, onde os vértices são os processadores e as arestas são os canais de comunicação. Dessa forma, os processadores comunicam-se entre si através do envio de mensagens através desses canais.

Na seção 2.1, definiremos alguns conceitos básicos sobre grafos que serão utilizados no decorrer deste trabalho. Na seção 2.2, apresentaremos exemplos de algumas redes de interconexão mais comuns e suas características.

\subsection{Definições básicas}

Esta seção é baseada no livro de Bondy e Murty [BM76].

Um grafo não-orientado $G_{r}$ é uma tripla $\left(V_{G}, E_{G}, \psi_{G}\right)$, onde $V_{G}$ é o conjunto de vértices de $G, E_{G}$ é o conjunto de arestas de $G$ e $\psi_{G}^{\prime}$ é a função de incidência que associa a cada par de vértices um par não-ordenado de vértices de $G$ (não necessariamente distintos).

Se $e$ é uma aresta do grafo $G$ e $\psi_{G}(e)=(u, v),\{u, v\} \in V_{G}$, então dizemos que $u$ e $v$ são extremos de e e que $e$ incide em $u$ (e em $v$ ). Se $u$ e $v$ são extremos de uma aresta $e$, então dizemos que $u$ é adjacente a $v$ e que $u$ e $v$ são vértices adjacentes. Duas arestas com um extremo em comum são chamadas adjacentes.

A ordem de um grafo $G$ é o número de vértices de $G$. O grau de um vértice $v$ num grafo $G, g_{G}(v)$, é o número de arestas que incidem em $v$. Um grafo $G$ é $k$-regular se 
$g_{G}(v)=k$, para todo $v \in V_{G}$.

Um caminho em um grafo é uma seqüência finita e não-vazia, $C=\left(v_{0}, e_{1}, v_{1}, \ldots, e_{k}, v_{k}\right)$, cujos termos são alternadamente vértices $v_{i}$ e arestas $e_{j}$, tal que, para todo $i, 1 \leq i \leq k$, os extremos de $e_{i}$ são $v_{i-1}$ e $v_{i}$ e todos os vértices são distintos. Dizemos que $C$ é um caminho de $v_{0}$ a $v_{k}$ e que os vértices $v_{0}$ e $v_{k}$ são a origem e o término de $C$, respectivamente. $\mathrm{O}$ inteiro $k$ é o comprimento de $C$.

Sejam $u$ e $v$ vértices de um grafo $G$. A distância de $u$ a $v$ em $G$, denotada por distância $(u, v)$, é o comprimento de um caminho mais curto de $u$ a $v$ em $G$. Se não existe um caminho de $u$ a $v$, então definimos que distância $(u, v)$ como sendo infinito.

Um grafo $H$ é um subgrafo de um grafo $G$, se $V_{H} \subseteq V_{G}, A_{H} \subseteq A_{G}$ e para toda aresta de $H$ seus extremos em $H$ sào também seus extremos em $G_{r}$.

Um grafo $G$ é conexo se para todo par de vértices distintos $u, v$ em $G$, existe um caminho de $u$ para $v$.

\subsection{Exemplos de redes de interconexão}

É comum modelar uma rede de interconexão por meio de um grafo finito não-orientado, onde os nós representam os processadores e as arestas, os canais de comunicação bidirecionais entre os mesmos.

Serão utilizados como medidas de desempenho de uma rede de interconexão o seu diâmetro e o seu grau máximo. O diâmetro é a distância máxima entre dois nós quaisquer na rede de interconexão e o grau máximo é o número máximo de arestas que incidem em um nó da rede de interconexão. Estes parâmetros são importantes, pois o diâmetro fornece um limite inferior para o tempo de comunicação entre quaisquer dois nós da rede, enquanto o grau máximo de um nó da rede descreve o maior número de conexões feitas simultaneamente em um único processador.

As definições das próximas seções são baseadas em [MSSSb].

\subsubsection{Hipercubos}

O hipercubo de dimensão $n$, a ser denotado por $Q(n)$, é também conhecido como $n$-cubo binário. Esta rede pode ser representada por um grafo cujos nós são rotulados por cadeias (strings) binárias de comprimento $n$, cujas arestas ligam dois nós com rótulos que diferem 
em apenas uma posição de bit. Cada bit do rótulo corresponde a uma dimensão do hipercubo.

Veja na Figura 2.1 como podemos representar um hipercubo de dimensão 3.
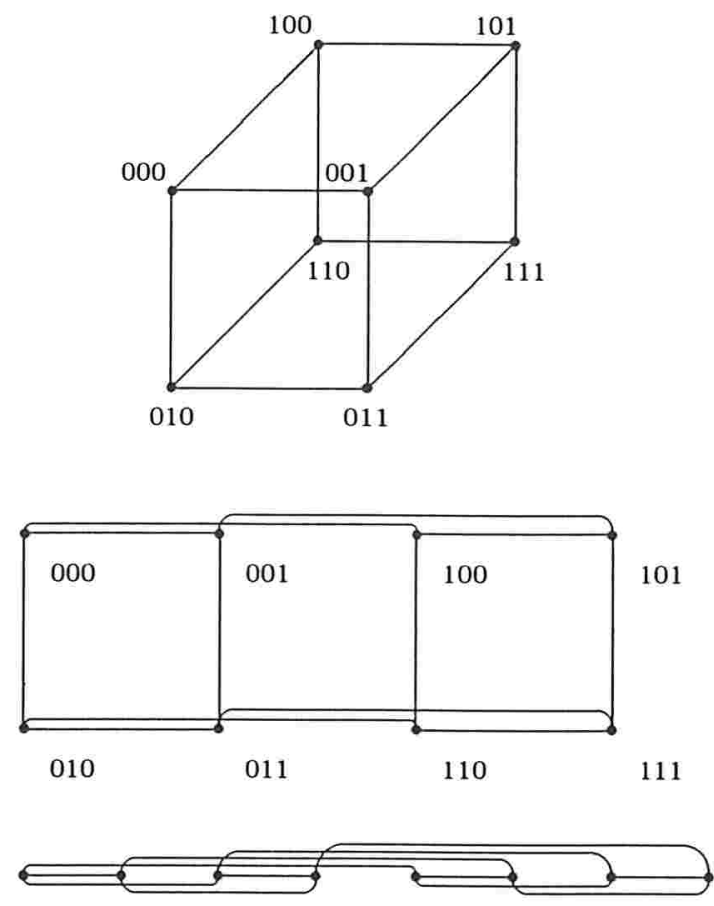

Figura 2.1: 3-cubos binários.

Um hipercubo de dimensão $n$ possui $2^{n}$ nós. $n 2^{n-1}$ arestas, diâmetro igual a $n$, grau máximo igual a $n$ e é $n$-regular.

\subsection{2 Árvores binárias}

A árvore binária completa de altura $n, B(n)$, é o grafo cujos nós são representados por cadeias binárias de comprimento no máximo $n$ e cujas arestas ligam cada cadeia $x$ de comprimento $i(0 \leq i \leq n)$ com todas as cadeias $x a, a \in\{0,1\}$, de comprimento $i+1$. $\mathrm{O}$ nó $e$, onde $e$ é uma cadeia vazia de comprimento 0 , é a raiz de $B(n)$. Um nó $x$ está no nível $i, i \geq 0$, em $B(n)$, se $x$ é uma cadeia de comprimento $i$. Uma árvore binária (não necessariamente completa) é um subgrafo conexo de $B(n)$, para algum $n \geq 0$. A Figura 2.2 ilustra um exemplo de árvore binária completa de altura igual a 2.

Uma árvore binária completa de altura $n$ possui $2^{n+1}-1$ nós, $2^{n+1}-2$ arestas, $2 n$ de diâmetro e grau máximo igual a 3 . 


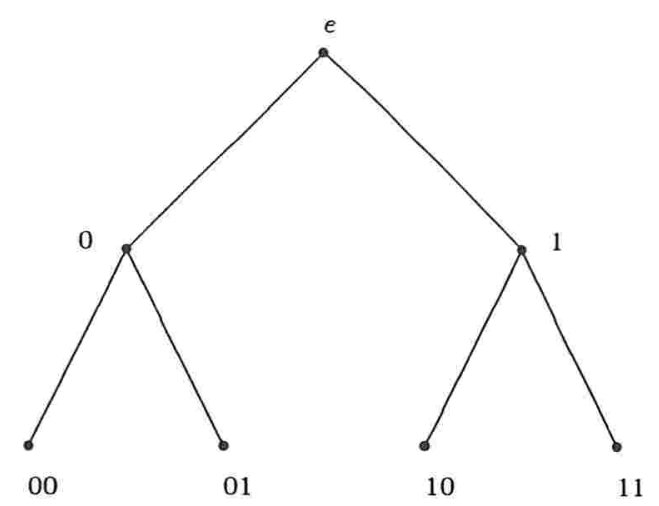

Figura 2.2: Árvore binária completa de altura 2.

\subsubsection{Grades}

A grade de dimensão $n$ ou grade $n$-dimensional $a_{0} \times a_{1} \times \ldots \times a_{n-1}$, denotada por $\left[a_{0} \times\right.$ $\left.a_{1} \times \ldots \times a_{n-1}\right]$, onde $a_{i}$ é um inteiro positivo para $0 \leq i<n$, é um grafo cujos nós são todos $n$-tuplas de inteiros não-negativos $\left(z_{0}, z_{1}, \ldots, z_{n-1}\right)$, onde $0 \leq z_{i}<a_{i}$ para todo $i$ $(0 \leq i<n)$, e cujas arestas conectam $n$-tuplas que diferem em uma, e só uma, coordenada e o valor absoluto da diferença dessas coordenadas é de uma unidade. Veja a Figura 2.3.

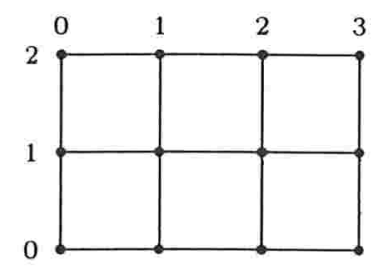

Figura 2.3: Grade $[3 \times 4]$.

Uma grade de dimensão $n$ possui $a_{0} a_{1} \ldots a_{n-1}$ nós, $\left(a_{0}-1\right) a_{1} \ldots a_{n}+a_{0}\left(a_{1}-1\right) \ldots a_{n}+$ $a_{0} a_{1} \ldots a_{n-2}\left(a_{n-1}-1\right)$ arestas, $\left(a_{0}-1\right)+\left(a_{1}-1\right)+\ldots+\left(a_{n-1}-1\right)$ de diâmetro e grau máximo igual a $2 n$, para $a_{i} \geq 3$.

\subsubsection{Grades toroidais}

A grade toroidal de dimensão $n, T\left[a_{0} \times a_{1} \times \ldots \times a_{n-1}\right]$, é um grafo cujos nós são $n$-tuplas de inteiros não-negativos $\left(z_{0}, z_{1}, \ldots, z_{n-1}\right)$, onde $0 \leq z_{i}<a_{i}$ para todo $i(0 \leq i<n)$, e dois nós $z$ e $z^{\prime}$ são adjacentes se

$$
\begin{aligned}
z & =\left(z_{0}, z_{1}, \ldots, z_{i}, \ldots, z_{n-1}\right) \\
z^{\prime} & =\left(z_{0}, z_{1}, \ldots, z_{i} \pm 1 \bmod a_{i}, \ldots, z_{n-1}\right)
\end{aligned}
$$




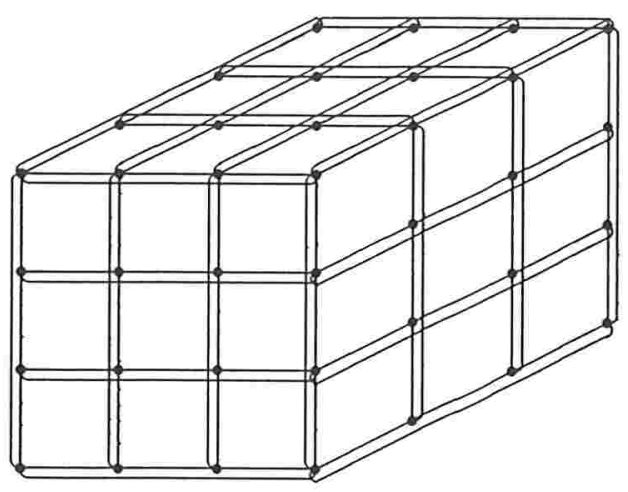

Figura 2.4: 3-cubo 4-ário.

para todo $i(0 \leq i<n)$.

O $n$-cubo $r$-ário é uma grade toroidal com $n$ dimensões e $r$ nós em cada dimensão. $\mathrm{O}$ número de nós $N$, dimensão $n$ e o parâmetro $r$ estão relacionados pela equação

$$
N=r^{n} \text { ou } n=\log _{r} N \text {. }
$$

Nas dimensões menores, usaremos também $i, j, \ldots$ no lugar de $z_{0}, z_{1}, \ldots$ No 2-cubo $r$-ário, por exemplo, o nó $(i, j)$ é adjacente aos nós $(i, j \pm 1 \bmod r)$ e $(i \pm 1 \bmod r, j)$. Como exemplo, a Figura 2.4 ilustra um 3-cubo 4-ário.

Uma grade toroidal de dimensão $n$ possui $a_{0} a_{1} \ldots a_{n-1}$ nós, $\left(a_{0} a_{1} \ldots a_{n-1}\right) n$ arestas. $\left\lceil\frac{a_{0}-1}{2}\right\rceil+\left\lceil\frac{a_{1}-1}{2}\right\rceil+\ldots+\left\lceil\frac{a_{n-1}-1}{2}\right\rceil$ de diâmetro e grau máximo igual a $2 n$, para $a_{i} \geq 3$.

\subsubsection{Pirâmides}

A pirâmide de altura $n, P(n)$, é um grafo cujos nós são representados por três inteiros não-negativos $(i, x, y)$, onde $0 \leq i \leq n$ e $1 \leq x, y \leq 2^{i}$, e cujas arestas ligam um nó $(i, x, y)$ com os nós $\in\{(i+1, u, v) \mid u \in\{2 x, 2 x-1\}$ e $v \in\{2 y, 2 y-1\}\}$ e com todos vértices $(i, a, b)$, tal que $(x, y)$ e $(a, b)$ são adjacentes na malha $\left[2^{i} \times 2^{i}\right]$ para todo $i(0 \leq i \leq n) \mathrm{e}$ todo $x, y\left(1 \leq x, y \leq 2^{i}\right)$. A Figura 2.5 ilustra uma pirâmide de altura 2 .

Uma pirâmide de altura $n$ possui $\frac{1}{3}\left(4^{n+1}-1\right)$ nós, $4^{n+1}-2^{n+2}$ arestas, $2 n-1$ de diâmetro e grau máximo igual a 9 , para $n \geq 3$ [LW90]. 


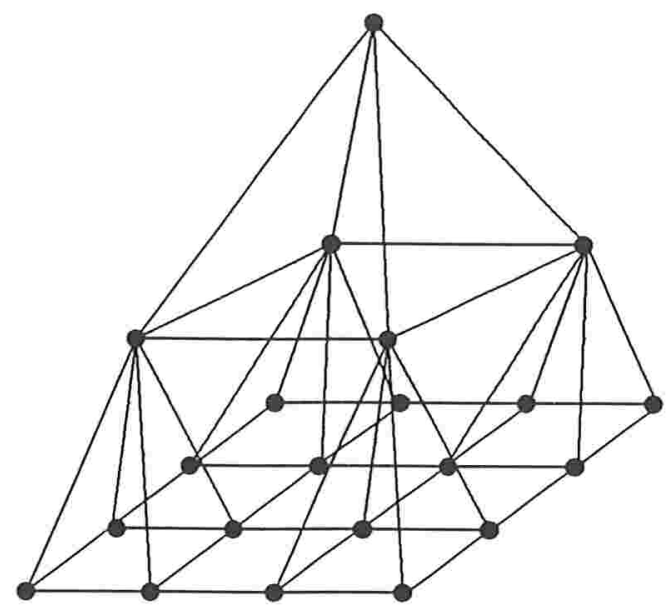

Figura 2.5: Pirâmide de altura 2.

\subsubsection{X-árvores}

A $X$-árvore de altura $n, X(n)$, é um grafo cujos nós são representados por cadeias binárias de comprimento no máximo $n$ e cada aresta liga uma cadeia $x$ de comprimento $i$ a uma cadeia $x a, a \in\{0,1\}$, de comprimento $i+1$, e quando binário $(x)<2^{i}-1, x$ é ligado com sucessor $(x)$, onde a função binário $(x)$ calcula o inteiro $x$ representado em notação binária e sucessor $(x)$ denota a única cadeia binária de comprimento $i$ tal que binário $(\operatorname{sucessor}(x))=$ binário +1 .

Informalmente, $\mathrm{X}$-árvore é uma árvore binária completa com arestas adicionais ligando nós consecutivos que estão em um mesmo nível. Veja um exemplo de uma rede X-árvore de altura igual a 2 na Figura 2.6.

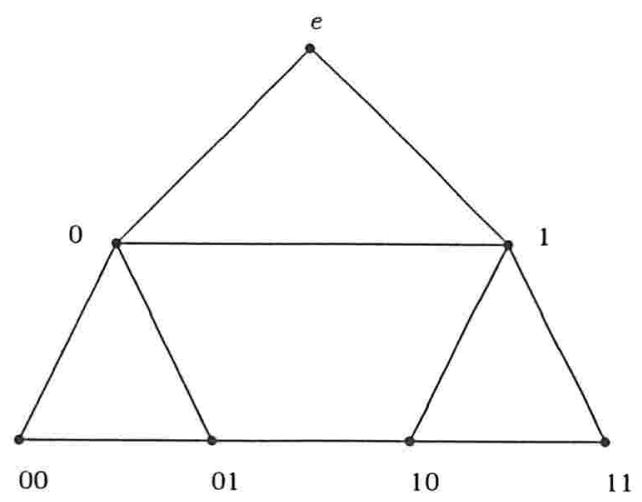

Figura 2.6: Rede X-árvore de altura 2.

Uma X-árvore de altura $n$ possui $2^{n+1}-1$ nós e $2^{n+2}-n-4$ arestas. $\mathrm{O}$ seu diâmetro 
é igual a $2 n-1$ e o seu grau máximo é igual a 5 , para $n \geq 3$.

\subsubsection{Malhas de árvores}

A malha de árvores de dimensão $n, M T(n)$, é o grafo cujos nós são pares $(x, y)$, onde $x$ e $y$ são cadeias binárias de comprimento no máximo $n$, com pelo menos uma das coordenadas com o comprimento exatamente $n$ e cujas arestas ligam $(x, y) \operatorname{com}(x a, y)$, quando $|x|<n$, ou ligam $(x, y)$ com $(x, y a)$, quando $|y|<n$, onde $|s|$ é o comprimento da cadeia binária $s$ e $a \in\{0,1\}$. A Figura 2.7 ilustra uma malha de árvores de dimensão 2.

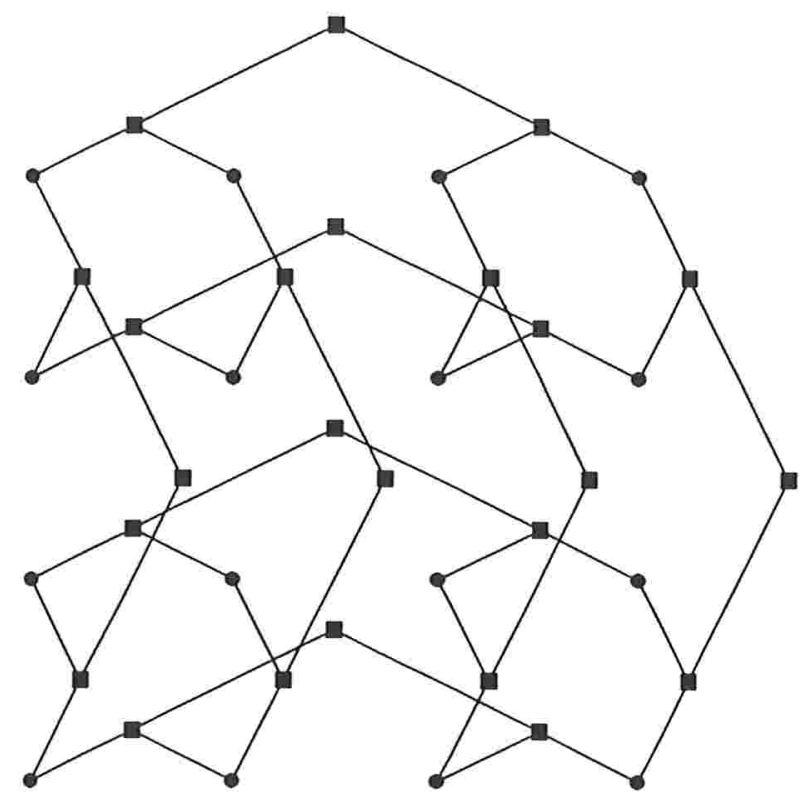

Figura 2.7: Malha de árvores de dimensão 2.

Uma malha de árvores de dimensão $n$ é construída a partir de uma grade $2^{n} \times 2^{n}$, adicionando alguns nós e arestas a fim de que sejam formadas árvores binárias em cada linha e em cada coluna da grade [Lei92].

Uma malha de árvores de dimensão $n$ possui $2^{n+1}\left(2^{n+1}-2^{n-1}-1\right)$ nós, $2^{n+2}\left(2^{n}-1\right)$ arestas, diâmetro igual a $4 n$ e grau máximo igual a 3 , para $n \geq 2$.

\subsubsection{Borboletas}

A borboleta (butterfly) de dimensão $n, B F(n)$, é um grafo cujos nós são pares $(w, i)$, onde $i$ é o nível ou dimensão do nó $(0 \leq i<n)$ e $w$ é um número binário de comprimento $n$ que corresponde à linha em que o nó está posicionado. 
Dois nós, $(w, i)$ e $\left(w^{\prime}, i^{\prime}\right)$, estão ligados por uma aresta se, e só se, $i^{\prime} \equiv i+1 \bmod n$ e:

1. $w$ e $w^{\prime}$ são idênticos (aresta direta), ou

2. $w$ e $w^{\prime}$ diferem exatamente no $(i+1)$-ésimo bit (aresta transversal).

Veja na Figura 2.8 uma borboleta de dimensão 3.

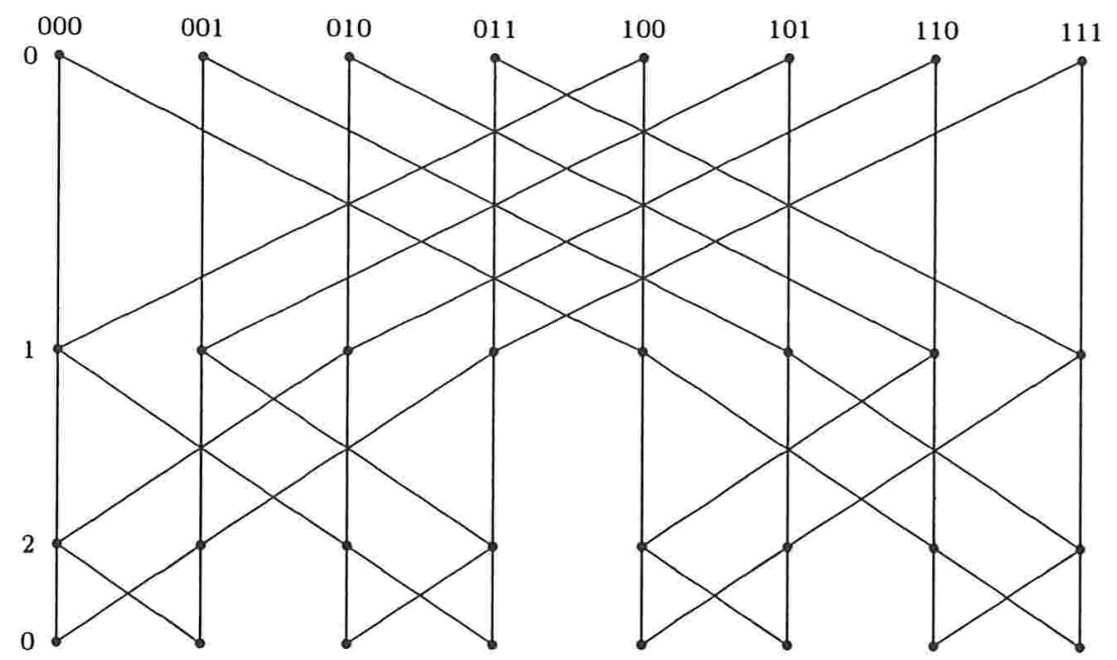

Figura 2.8: Borboleta de dimensão 3.

Uma borboleta de dimensão $n, n \geq 2$. possui $n 2^{n}$ nós, $n 2^{n+1}$ arestas, diâmetro igual a $n+\left\lfloor\frac{n}{2}\right\rfloor$, grau máximo igual a 4 e é 4-regular, para $n \geq 2$.

\subsubsection{Ciclos conectados em cubo}

A estrutura de ciclos conectados em cubo de dimensão $n, C C C(n)$, é construída a partir de um hipercubo de dimensão $n$, onde cada nó do hipercubo é substituído por um ciclo de $n$ nós no $C C C(n)$. A aresta de dimensão $i$ que incide em algum nó no hipercubo está conectada ao $i$-ésimo nó do ciclo correspondente no $C C C(n)$.

Cada nó no $C C C(n)$ é representado por um par $(w, i)$, onde $i(1 \leq i \leq n)$ é a posição do nó dentro do ciclo e $w$ é uma cadeia binária de comprimento $n$ que representa o rótulo do nó do hipercubo que corresponde ao ciclo.

Dois nós, $(w, i)$ e $\left(w^{\prime}, i^{\prime}\right)$, estão ligados por uma aresta se, e só se:

1. $w=w^{\prime}$ e $i-i^{\prime} \equiv \pm 1 \bmod n($ aresta de ciclo), ou 
2. $i=i^{\prime}$ e $w$ difere de $w^{\prime}$ precisamente no $i$-ésimo bit (aresta do hipercubo).

Veja na Figura 2.9 uma estrutura de ciclos conectados em cubos de dimensão 3.

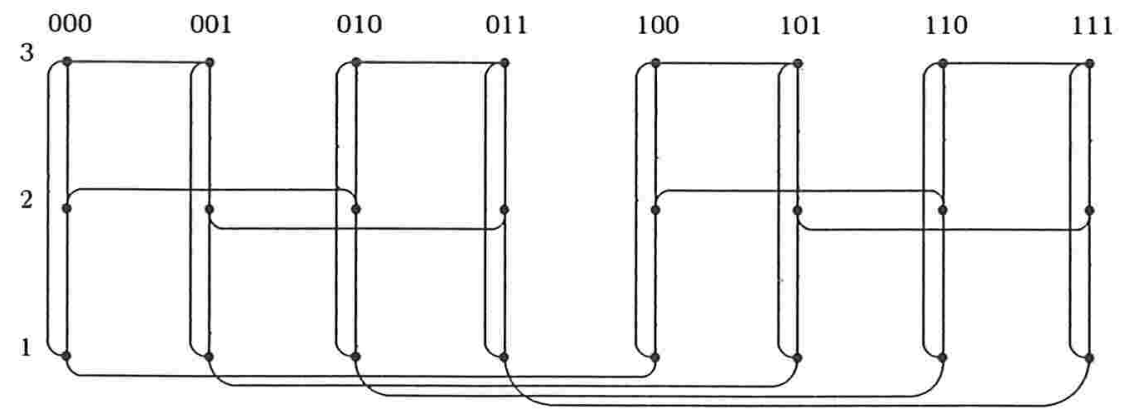

Figura 2.9: Ciclos conectados em cubos de dimensão 3.

Um $C C C(n)$ possui $n 2^{n}$ nós, $3 n 2^{n-1}$ arestas, grau máximo igual a 3 e é 3 -regular. $\mathrm{O}$ diâmetro de um $C C C(n)$ é igual a 6 , se $n=3$, senão $2 n+\left\lfloor\frac{n}{2}\right\rfloor-2$, se $n \geq 4$ [FHL97]. 


\section{Capítulo 3}

\section{Imersão de grafos}

A imersão de uma rede de interconexão em outra é uma questão muito importante no desenvolvimento e na análise de algoritmos paralelos. Através destas imersões, algoritmos originalmente desenvolvidos para uma determinada arquitetura podem ser mapeados para uma outra arquitetura.

Na seção 3.1, definiremos o que é uma imersão de grafos e as suas medidas de qualidades, dilatação, expansão e congestionamento. Na seção 3.2, apresentaremos alguns resultados já conhecidos sobre imersões de algumas redes de interconexão em seu hipercubo ótimo. Na seção 3.3 , apresentaremos dois métodos de imersão de um $m$-cubo $r$-ário no hipercubo, o método do dobramento recursivo [HS96, Son94] e o método do código de Gray [SS8S]. Finalizando, na seção 3.4, apontaremos uma diferença entre estes dois métodos.

\subsection{Definição}

Considere um grafo finito não-orientado denominado guest, $G=\left(V_{G}, E_{G}\right)$, e um grafo finito não-orientado host, $H=\left(V_{H}, E_{H}\right)$, onde $V$ e $E$ são os respectivos conjuntos de nós e arestas do grafo.

Uma imersão $\langle\alpha, \varphi\rangle$ de $G$ em $H$ é um mapeamento $\alpha$ um-para-um dos nós de $G$ aos nós de $H$,

$$
V_{G} \stackrel{a}{\longrightarrow} V_{H}
$$

juntamente com um mapeamento $\varphi$ das arestas de $G$ a caminhos de $H$,

$$
E_{G} \stackrel{\varphi}{\longrightarrow} C_{H},
$$


sendo $C_{H}$ conjunto de caminhos de $H$ tal que se $e=(u, v), e \in E_{G}$, então $\varphi(e)$ é um caminho de $H$ com extremos $\alpha(u)$ e $\alpha(v)$.

A qualidade de uma imersão $\langle\alpha, \varphi\rangle$ pode ser dada pela sua dilatação, expansão e congestionamento [KGGK94].

A dilatação é a distância máxima no grafo $H$ entre as imagens de nós adjacentes de $G$. Em outras palavras,

$$
\text { dilatação }=\max _{(x, y) \in E_{G}}\{\operatorname{distância}(\alpha(x), \alpha(y))\},
$$

onde distância $(a, b)$ denota o comprimento de um caminho mais curto em $H$ entre os nós $a$ e $b$. Ela representa o custo de comunicação após a imersão.

A expansão é a razào entre o número de nós de $H$ e o número de nós de $G$ :

$$
\text { expansão }=\frac{\left|V_{H}\right|}{\left|V_{G}\right|} .
$$

Intuitivamente, ela mede a utilização do processador.

$\mathrm{O}$ congestionamento de uma aresta $e^{\prime} \in E_{H}$ é dado por $\mid e \in E_{G}: e^{\prime}$ está no caminho $\varphi(e) \mid$. congestionamento da imersão $\langle\alpha, \varphi\rangle$ é definido como:

$$
\text { congestionamento }=\max _{e^{\prime} \in E_{H}}\left\{\mid e \in E_{G}: e^{\prime} \text { está no caminho } \varphi(e) \mid\right\} \text {. }
$$

O congestionamento caracteriza o tráfego que flui através das arestas de $E_{H}$.

\subsection{Imersão em hipercubos}

O hipercubo (n-cubo binário) é uma das mais versáteis e eficientes redes de interconexão para computação paralela. Uma das grandes razões para a popularidade do hipercubo é a sua capacidade de simular eficientemente muitas arquiteturas paralelas. Apresentaremos a seguir alguns resultados de imersões de algumas redes de interconexão no seu hipercubo ótimo. O hipercubo ótimo para um grafo $G$ é o menor hipercubo que possui pelo menos o mesmo número de nós que $G$.

\subsection{1 Árvores binárias}

A árvore binária completa $B(n)$, que possui $2^{n+1}-1$ nós, pode ser imersa no seu hipercubo ótimo $Q(n+1)$, que possui $2^{n+1}$ nós, com dilatação 2 . De fato, $B(n)$ pode ser 
imersa em $Q(n+1)$, de maneira que exatamente uma de suas arestas corresponderá a um caminho de distância 2 no hipercubo e as demais arestas ligarăo os nós correspondentes com distância 1 [BCLR86, BI85, Hav84, Neb74].

Não é possível realizar a imersão de uma árvore binária completa $B(n)$ em seu hipercubo ótimo $Q(n+1)$ com dilatação igual a 1 , pois $B(n)$ não é um subgrafo de $Q(n+1)$, para todo $n>1$ [MS88a].

Imersões de árvores binárias arbitrárias em hipercubos com dilatação pequena também têm sido estudadas. Monien e Sudborough [MS88a] descreveram uma técnica que permite a imersão de árvores binárias arbitrárias em seus respectivos hipercubos ótimos com dilatação 5 e expansão 1 .

\subsubsection{Grades}

Uma grade de dimensão $n,\left[a_{1} \times a_{2} \times \ldots \times a_{n}\right]$, é um subgrafo conexo do seu hipercubo ótimo se, e só se, $\left\lceil\log a_{1}\right\rceil+\left\lceil\log a_{2}\right\rceil+\ldots+\left\lceil\log a_{n}\right\rceil=\left\lceil\log a_{1}+\log a_{2}+\ldots+\log a_{n}\right\rceil$ [BS86, CC88].

Todas as grades de dimensão 2 podem ser imersas em seus respectivos hipercubos ótimos com dilatação 2 [Cha88]. Em [CC93], Chan e Chin descrevem um algoritmo que, dado a dimensão da grade, permite que cada nó do hipercubo determine em tempo constante que nó da grade que ele irá simular.

\subsubsection{Pirâmides}

A pirâmide $P(n)$, para todo $n>0$, pode ser imersa em seu hipercubo ótimo $Q(2 n+1)$ com dilatação 2 e congestionamento 2 [MLSS8]. A imersão é descrita recursivamente [MS8Sb].

As pirâmides $P(1), P(2)$ e $P(3)$ possuem graus máximos 5,7 e 9 , respectivamente, enquanto que seus hipercubos ótimos, $Q(3), Q(5)$ e $Q(7)$, possuem graus máximos iguais a 3.5 e 7 , respectivamente. Portanto, o congestionamento 2 é necessário para qualquer imersão destas pirâmides em seus hipercubos ótimos. Ainda não se sabe se é possível realizar imersões de $P(n)$ em $Q(2 n+1)$, para $n>3$, com dilatação 2 e congestionamento 1 . No entanto, qualquer imersão de uma pirâmide em seu hipercubo ótimo deve possuir dilatação pelo menos 2, pois as pirâmides possuem ciclos de tamanho impar [LW90]. 


\subsubsection{X-árvores}

A imersão de uma X-árvore $X(n)$ em seu hipercubo ótimo $Q(n+1)$, para todo $n>0$, pode ser feita com dilatação 2 e congestionamento 2. A técnica de imersão é descrita recursivamente [MSSSb].

\subsubsection{Malhas de árvores}

A imersão de uma malha de árvores $M T(n)$ em um hipercubo $Q(2 n+2)$ com dilatação 2 é facilmente descrita utilizando uma imersão com dilatação 2 de uma árvore binária completa $B(n)$ no hipercubo $Q(n+1)$ e observando que a $M T(n)$ é um produto de duas destas árvores.

\subsubsection{Borboletas e ciclos conectados em cubo}

A borboleta $B F(n)$ e a estrutura de ciclos conectados em cubo $C C C(n)$ podem ser imersas com dilatação $1+(n \bmod 2)$ em seus hipercubos ótimos $Q(n+\lceil\log n\rceil)$, isto é, $B F(n)$ e $C C C(n)$ são subgrafos de $Q(n+\lceil\log n\rceil)$ quando as suas dimensões forem par [GHR90].

\subsection{Imersão do $m$-cubo $r$-ário no $n$-cubo binário}

Nesta seção, serão descritos o método do Dobramento Recursico [HS96, Son94] e o método do Código de Gray [SS88] para imersão do $m$-cubo $r$-ário no $n$-cubo binário.

\subsubsection{Método do dobramento recursivo}

Consideremos como grafo $G$ o $m$-cubo $r$-ário e como grafo $H$ o $n$-cubo binário de igual número $N$ de nós. Suporemos ainda que $r$ é uma potência de 2. $r=2^{s}$, com inteiro $s \geq 1$. Temos

$$
\begin{gathered}
N=2^{n}=r^{m}=2^{s m} \\
n=s m \text { ou } n=m \log r .
\end{gathered}
$$

Vamos mostrar uma imersão do grafo $G$ em $H$ com dilatação 1. Como os dois grafos têm igual número de nós, temos obviamente expansão igual a 1 .

Consideremos os nós do grafo $H$, ou seja, do $n$-cubo binário,

$$
0,1,2, \ldots, 2^{n}-1
$$


em sua representação binária

$$
\underbrace{00 \ldots 00}_{n}, 00 \ldots 01, \ldots, 11 \ldots 10,11 \ldots 11
$$

Vamos dispor esses nós numa matriz $m$-dimensional $\underbrace{r \times r \times \cdots \times r}_{m}$, denotada por $T(r, m)$. Os elementos de $T(r, m)$ são números binários de $m \log r$ bits cada.

Sem perda de generalidade, vamos considerar a seguir o caso $m=2$. O caso geral será tratado em seguida.

Caso $m=2$

Os nós do grafo $H, n$-cubo binário, são dispostos numa matriz quadrada $r \times r$ denotada por

$$
T(r, 2)=\left(t_{i j}\right)=\left(\begin{array}{cccc}
t_{00} & t_{01} & \ldots & t_{0, r-1} \\
t_{10} & t_{11} & \ldots & t_{1, r-1} \\
\vdots & \vdots & \ddots & \vdots \\
t_{r-1,0} & t_{r-1,1} & \ldots & t_{r-1, r-1}
\end{array}\right)
$$

onde $0 \leq i, j<r, r=2^{n / 2}$ e cada $t_{i j}$ é um número binário de $n=2 \log r$ bits.

Para a imersão de $G$ em $H$ usaremos o seguinte mapeamento $\alpha$ :

$$
\text { nó }(i, j) \text { de } G \stackrel{\alpha}{\longrightarrow} \text { nó } t_{i j} \text { de } H \text {. }
$$

Vamos mostrar que, com a definição de $T(r, 2)$ a ser dada, a imersão dada pelo mapeamento $\alpha$ acima tem dilatação 1 .

Notação 3.3.1 Denotemos por $00 T(r, 2)=\left(t_{i j}^{\prime}\right)$ onde $t_{i j}^{\prime}=00 t_{i j}$, isto é, 00 seguidos dos bits de $t_{i j}$. Em outras palavras, $00 T(r, 2)$ é a matriz $T(r, 2)$ cujos elementos são precedidos por 00 .

$$
00 T(r, 2)=\left(\begin{array}{lll}
00 t_{00} & \ldots & 00 t_{0, r-1} \\
\vdots & \ddots & \vdots \\
00 t_{r-1,0} & \ldots & 00 t_{r-1, r-1}
\end{array}\right)
$$

Analogamente, temos $01 T(r, 2), 10 T(r, 2)$ e $11 T(r, 2)$.

Os bits que precedem $T(r, 2)$ são ditos bits concatenados a $T(r, 2)$. 
Notação 3.3.2 Seja

$$
T(r, 2)=\left(\begin{array}{cccc}
t_{00} & t_{01} & \ldots & t_{0, r-1} \\
t_{10} & t_{11} & \ldots & t_{1, r-1} \\
\vdots & \vdots & \ddots & \vdots \\
t_{r-1,0} & t_{r-1,1} & \ldots & t_{r-1, r-1}
\end{array}\right)=\left(\begin{array}{c}
l_{0} \\
l_{1} \\
\vdots \\
l_{r-1}
\end{array}\right)=\left(\begin{array}{llll}
c_{0} & c_{1} & \ldots & c_{r-1}
\end{array}\right)
$$

onde

$$
l_{i}=\left(\begin{array}{llll}
t_{i 0} & t_{i 1} & \ldots & t_{i, r-1}
\end{array}\right) \text { e } c_{j}=\left(\begin{array}{c}
t_{0 j} \\
t_{1 j} \\
\vdots \\
t_{r-1, j}
\end{array}\right)
$$

Usuremos a seguinte notação:

$$
\begin{gathered}
\ddagger T(r, 2)=T(r, 2) \\
\downarrow T(r, 2)=\left(\begin{array}{llll}
c_{r-1} & \ldots & c_{1} & c_{0}
\end{array}\right) \\
\uparrow T(r, 2)=\left(\begin{array}{c}
l_{r-1} \\
\vdots \\
l_{1} \\
l_{0}
\end{array}\right) \\
\\
\text { 牛 } T(r, 2)=\uparrow(\$ T(r, 2))
\end{gathered}
$$

Na Notação 3.3.2, a seta vertical indica o sentido de crescimento (de cima para baixo ou de baixo para cima) do índice $i$ de $t_{i j}$. A seta horizontal indica o sentido de crescimento (da esquerda para direita ou da direita para a esquerda) do índice $j$ de $t_{i j}$.

Definição 3.3.1 Vamos definir $T(r, 2)$ por meio da seguinte recorrência.

$$
\begin{aligned}
T(2,2) & =\left(\begin{array}{ll}
00 & 01 \\
10 & 11
\end{array}\right), \\
T(r, 2) & =\left(\begin{array}{ll}
00 \uparrow T\left(\frac{r}{2}, 2\right) & 01 \nleftarrow T\left(\frac{r}{2}, 2\right) \\
10 \uparrow T\left(\frac{r}{2}, 2\right) & 11 \nLeftarrow T\left(\frac{r}{2}, 2\right)
\end{array}\right), \quad r>2 .
\end{aligned}
$$


Observemos na definição acima o seguinte. Tomando como sentido normal de crescimento dos índices como $\downarrow$ (isto é, índice $i$ de cima para baixo e índice $j$ da esquerda para a direita), podemos notar que cada bit concatenado corresponde a uma dimensão, com 0 indicando o sentido considerado normal e 1 o sentido inverso.

Teorema 3.3.1 Seja $G$ o 2-cubo r-ário, com $r=2^{s}$ e seja $H$ o n-cubo binário, com $n=2 \log r$. Com a Definição 3.3 .1 de $T(r, 2)$ e usando o mapeamento

$$
\text { nó }(i, j) \text { de } G \stackrel{\alpha}{\longrightarrow} \text { nó } t_{i j} \text { de } H,
$$

teremos uma imersão de $G$ em $H$ de dilatação 1 , ou seja, nós adjacentes de $G$, u e v, são mapeados a nós adjacentes de $H, \alpha(u)$ e $\alpha(v)$.

\section{Prova:}

Por indução sobre $r$.

Para $r=2$,

$$
T(2,2)=\left(\begin{array}{ll}
t_{00} & t_{01} \\
t_{10} & t_{11}
\end{array}\right)=\left(\begin{array}{ll}
00 & 01 \\
10 & 11
\end{array}\right)
$$

Os pares de elementos de $T(2,2)$, na horizontal e na vertical, são adjacentes pois diferem de um bit. $T(r, 2)$.

Vamos supor válido o teorema para o caso $\frac{r}{2}$. Vamos mostrar que o teorema vale para

Pela hipótese de indução, temos em $T\left(\frac{r}{2}, 2\right)$ ou $\downarrow T\left(\frac{r}{2}, 2\right)$,

$$
\begin{aligned}
& t_{i j} \text { e } t_{i \pm 1 \bmod \frac{r}{2}, j} \text { são adjacentes e } \\
& t_{i j} \text { e } t_{i, j \pm 1 \bmod \frac{r}{2}} \text { são adjacentes. }
\end{aligned}
$$

Isso também vale para $\nleftarrow T\left(\frac{r}{2}, 2\right), \uparrow T\left(\frac{r}{2}, 2\right)$ e $\uparrow T\left(\frac{r}{2}, 2\right)$, uma vez que a inversão das linhas ou colunas não altera as características de adjacência.

Assim, cada um dos $\downarrow T\left(\frac{r}{2}, 2\right), \nleftarrow T\left(\frac{r}{2}, 2\right), \uparrow T\left(\frac{r}{2}, 2\right)$ e $\left\{T\left(\frac{r}{2}, 2\right)\right.$ forma um 2-cubo $\left(\frac{r}{2}\right)$-ário.

Consideremos

$$
\begin{aligned}
T(r, 2) & =\left(\begin{array}{cc}
00 \pitchfork T\left(\frac{r}{2}, 2\right) & 01 \uplus T\left(\frac{r}{2}, 2\right) \\
10 \nrightarrow T\left(\frac{r}{2}, 2\right) & 11 \uparrow T\left(\frac{r}{2}, 2\right)
\end{array}\right) \\
& =\left(\begin{array}{cc}
\text { primeiro quadrante } & \text { segundo quadrante } \\
\text { terceiro quadrante } & \text { quarto quadrante }
\end{array}\right)
\end{aligned}
$$




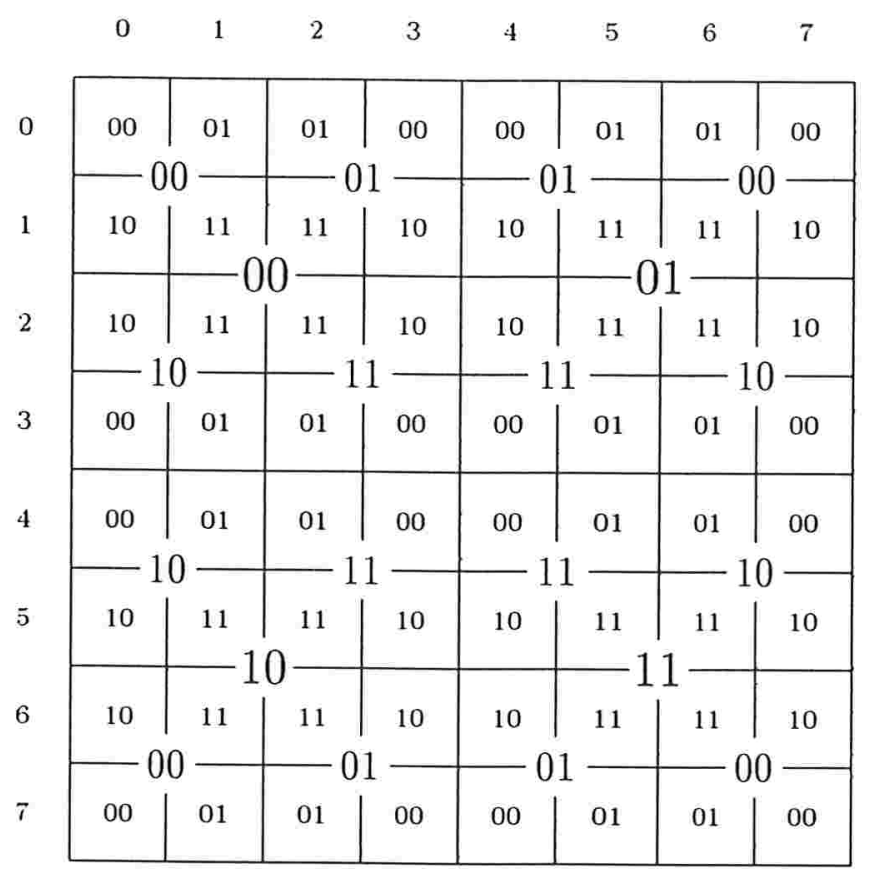

Figura 3.1: Disposição do 6-cubo binário por $T(8,2)$

Cada um dos quadrantes constitui um subcubo, cujos nós possuem os mesmos 2 bits iniciais. Conforme visto, esses subcubos formam 2-cubos $\left(\frac{r}{2}\right)$-ários. Basta mostrar, portanto, que os quatro quadrantes estão ligados pelas suas bordas (inclusive as bordas toroidais entre os lados superior e inferior e entre as extremidades esquerda e direita).

Consideremos a última linha do primeiro quadrante e a primeira linha do terceiro quadrante. Os elementos correspondentes destas duas linhas diferem apenas no seu primeiro bit, uma vez que a última linha de $\nmid T\left(\frac{r}{2}, 2\right)$ é idêntica a primeira linha de $\uparrow T\left(\frac{r}{2}, 2\right)$, por definição. Assim, eles estão interligados. Do mesmo modo, a última linha do segundo quadrante e a primeira linha do quarto quadrante diferem apenas no segundo bit e estão interligadas. Analogamente, mostramos a interligação das outras bordas.

Temos assim um método de arranjar os nós de um $n$-cubo binário de modo que eles formam um 2-cubo $r$-ário. A Figura 3.1 é obtida diretamente da definição de $T(r, 2)$ e é instrutivo observá-la com cuidado. Esta figura mostra $T(8,2)$. No centro de cada quadrante, representamos os 2 primeiros bits dos elementos pertencentes ao quadrante. Cada quadrante, por sua vez, é dividido em quatro quadrantes, cujos centros contêm os 2 bits seguintes dos elementos a eles pertencentes e assim sucessivamente. 


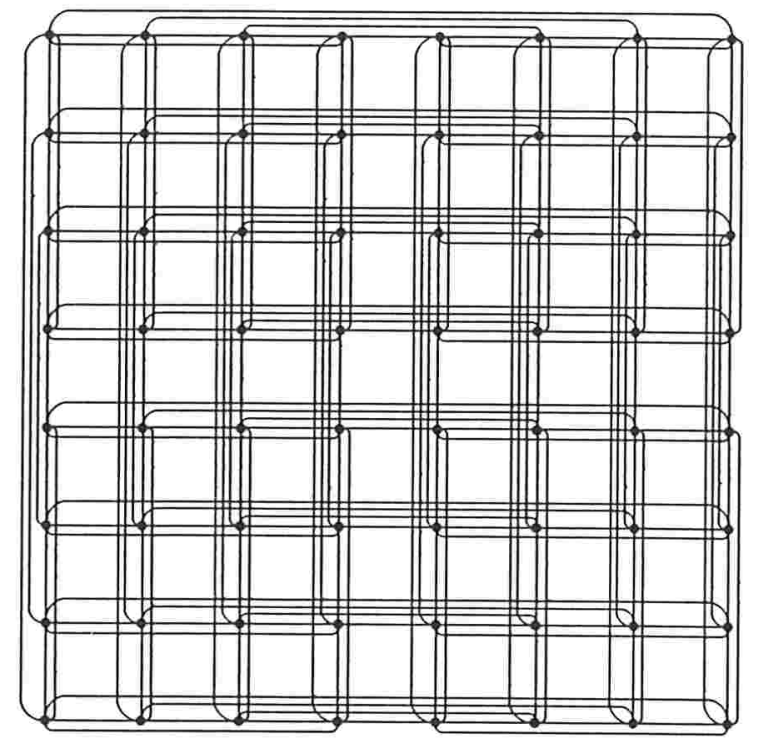

Figura 3.2: Disposição dos nós do 6-cubo binário por $T(8,2)$

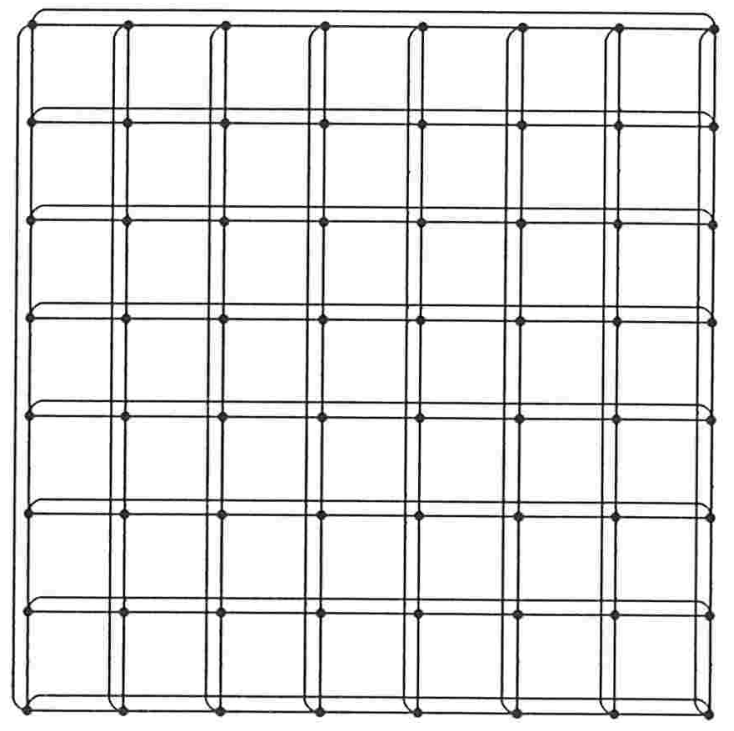

Figura 3.3: 2-cubo 8-ário 
Na Figura 3.2, mostramos a disposição dos nós do 6-cubo binário segundo $T(8,2)$. Obviamente, ele contém o 2-cubo 8-ário, Figura 3.3.

\section{Caso $m=3$}

$\mathrm{O}$ que foi visto pode ser generalizado para o $m$-cubo $r$-ário, com qualquer $m>2$. É instrutivo estudar o caso $m=3$, que ainda pode ser ilustrado de maneira adequada.

Consideremos um $n$-cubo binário e um 3-cubo $r$-ário, $r=2^{s}$, com $n=3 \log r$. Analogamente ao caso anterior, temos a definição de $T(r, 3)$, conforme a Figura 3.4. $T(r, 3)=\left(t_{i j k}\right)$ é uma matriz 3-dimensional $r \times r \times r$ de números binários de $3 \log r$ bits.

$T(r, 3)$ é obtido a partir de duas cópias de $T(r, 2)$, uma das quais precedida de 0 e a outra de 1. A dimensão adicional é representada por uma seta adicional, denotada por $\nearrow$ ou $\swarrow$, que representa o sentido de crescimento do novo índice $k$ de $t_{i j k}$, conforme o bit concatenado.

\section{Caso geral: $m$ qualquer}

Agora, podemos dar a definição geral de $T(r, m)$. Para ajudar a sua compreensão, o leitor poderá recorrer aos casos mais simples de $m=2$ e $m=3$.

$T(2, m)$ é uma matriz m-dimensional com tamanho 2 ao longo de cada dimensão, denotada por $\left(t_{e_{0}, e_{1}, \ldots, e_{m-1}}\right)$, onde um elemento geral $t_{e_{0}, e_{1}, \ldots, e_{m-1}}$ é definido como:

$$
t_{e_{0}, e_{1}, \ldots, e_{m-1}}=e_{0}, e_{1}, \ldots, e_{m-1}
$$

com cada $e_{i}$ igual a 0 ou 1.

$T(r, m)=\left(t_{e_{0}, e_{1}, \ldots, e_{m-1}}\right)$ é uma matriz $m$-dimensional com tamanho $r$ ao longo de cada dimensão, onde cada $e_{i}$ está entre 0 e $r-1$.

Dada certa matriz $T=\left(t_{e_{0}, e_{1}, \ldots, e_{m-1}}\right)$, denotemos por $T^{d_{0}, d_{1}, \ldots, d m-1}$ uma nova matriz derivada de $T$, onde alguns dos índices ao longo de determinadas dimensões estão invertidos. Quando $d_{i}$ é 0 , não há inversão a longo da dimensão $i$. Quando $d_{i}$ é 1 , há então uma inversão ao longo da dimensão $i$. Mais especificamente, podemos definir o seguinte:

$$
T^{0,0, \ldots, 0}=T,
$$

$T^{d_{0}, \ldots, d_{t-1}, 1, d_{i+1}, \ldots, d_{m-1}}=$ a matriz obtida a partir de $T^{d_{0}, \ldots, d_{i-1}, 0, d_{i+1}, \ldots, d_{m-1}}$ depois da inversão dos índices ao longo da dimensão $i$. 

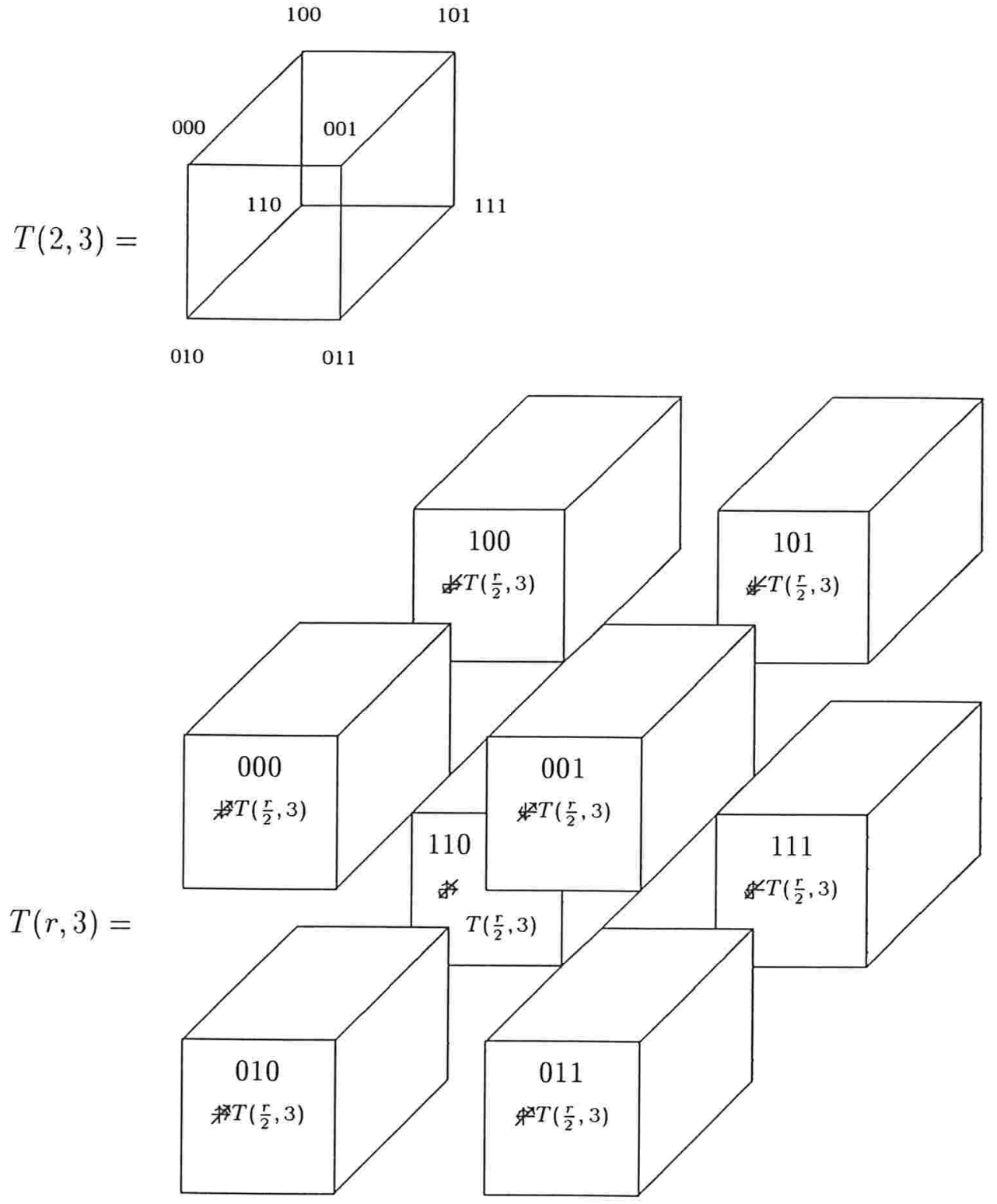

Figura 3.4: Definição de $T(r, m)$ para caso $m=3$ 
Relembrando o caso $m=2$. Com esta notação $\nleftarrow T$ pode ser denotada por $T^{0,1}$ e $\uparrow T$ por $T^{1,0}$.

Conforme visto anteriomente, dada $T=\left(t_{e_{0}, e_{1}, \ldots, e_{m-1}}\right), d_{0} d_{1} \ldots d_{m-1} T$ denota uma nova matriz com bits $d_{0} d_{1} \ldots d_{m-1}$ concatenados aos elementos de $T$ :

$$
d_{0} d_{1} \ldots d_{m-1} T=\left(d_{0} d_{1} \ldots d_{m-1} t_{e_{0}, e_{1}, \ldots, e_{m-1}}\right) .
$$

Agora, estamos pronto para definir $T(r, m)$.

Primeiro, vamos particionar $T(r, m)=\left(t_{e_{0}, e_{1}, \ldots, e_{m-1}}\right)$ em submatrizes $T_{d_{0}, d_{1}, \ldots, d_{m-1}}$, onde cada $d_{i}$ é 0 ou 1. Cada submatriz corresponde a uma partição de $T(r, m)$ e os índices $d_{i}$ indicam a faixa de $e_{i}$, como segue:

$$
\begin{aligned}
& d_{i}=0 \text { corresponde à faixa }\left(0 \leq e_{i}<\frac{r}{2}\right) \\
& \left.d_{i}=1 \text { corresponde à faixa }\left(\frac{r}{2} \leq e_{i}<r\right)\right)
\end{aligned}
$$

para $i=0,1, \ldots, m-1$.

Cada submatriz será definida pela concatenação dos bits $d_{0} d_{1} \ldots d_{m-1}$ ao elementos de $T^{d_{0}, \ldots, d_{m-1}}\left(\frac{r}{2}, m\right)$, como segue:

$$
T_{d_{0}, d_{1}, \ldots . d_{m-1}}=d_{0} d_{1} \ldots d_{m-1} T^{d_{0}, \ldots, d_{m-1}}\left(\frac{r}{2}, m\right)
$$

para todo $d_{i}=0,1$.

Teorema 3.3.2 Seja $G$ um m-cubo r-ário, com $r=2^{s}$ e seja $H$ um n-cubo binário, com $n=m \log r$. Com $T(r, m)$ construída como acima e usando o mapeamento $\alpha$ :

$$
\text { nó }\left(e_{0}, e_{1}, \ldots, e_{m-1}\right) \text { de } G \stackrel{\alpha}{\longrightarrow} \text { nó } t_{e_{0}, e_{1}, \ldots, e_{m-1}} \text { de } H \text {, }
$$

teremos uma imersão de $G$ em $H$ de dilatação 1 , com nós adjacentes, u ev, de $G$ mapeados aos nós adjacentes de $H, \alpha(u)$ e $\alpha(v)$.

Prova: A prova é similar ao teorema 3.3.1, por indução em $r$.

Para $r=2, T(2, m)=\left(t_{e_{0}, e_{1}, \ldots, e_{m-1}}\right)$, onde cada elemento

$$
t_{e_{0}, e_{1}, \ldots, e_{m-1}}=e_{0}, e_{1}, \ldots, e_{m-1}
$$

com cada $e_{i}$ igual a 0 ou 1.

Os pares de elementos de $T(2, m)$ 


$$
\begin{gathered}
t_{e_{0}, e_{1}, \ldots, e_{i}, \ldots, e_{m-1}} \mathrm{e} \\
t_{e_{0}, e_{1}, \ldots, e_{i \pm 1} \bmod 2, \ldots, e_{m-1}}
\end{gathered}
$$

são obviamente adjacentes, uma vez que eles diferem em exatamente um bit.

Vamos supor que o teorema é válido para $T\left(\frac{r}{2}, m\right)$. Mostraremos que ele vale também para $T(r, m)$.

Consideremos os pares elementos de $T\left(\frac{r}{2}, m\right)=T^{0,0, \ldots, 0}\left(\frac{r}{2}, m\right)$,

$$
\begin{gathered}
t_{e_{0}, e_{1}, \ldots, e_{i}, \ldots, e_{m-1}} \mathrm{e} \\
t_{e_{0}, e_{1}, \ldots, e_{i \pm 1} \bmod \frac{r}{2}, \ldots, e_{m-1}}
\end{gathered}
$$

para algum $i(0 \leq i<m)$. Pela hipótese da indução, estes elementos são adjacentes.

Isto é verdade também para todos $T^{d_{0}, \ldots, d_{m-1}}$, com $d_{i}=0,1$, visto que a mera inversão dos índices não altera a propriedade de adjacência. Todos da forma $T^{d_{0}, \ldots, d_{m-1}}$ formam então $m$-cubos $\left(\frac{r}{2}\right)$-ários.

Consideremos $T(r, m)$ definida em termos de submatrizes de acordo com a seção anterior. Cada uma das submatrizes, definida como $T^{d_{0}, \ldots, d_{m-1}}\left(\frac{r}{2}, m\right)$, forma um $m$-cubo $\left(\frac{r}{2}\right)$-ário. Consideremos quaisquer duas submatrizes da forma

$$
\begin{gathered}
T^{d_{0}, \ldots, d_{i-1}, 0, d_{i+1}, \ldots, d_{m-1}}\left(\frac{r}{2}, m\right) \mathrm{e} \\
T^{d_{0}, \ldots, d_{i-1}, 1, d_{i+1}, \ldots, d_{m-1}}\left(\frac{r}{2}, m\right) .
\end{gathered}
$$

Os elementos da primeira submatriz da forma

$$
t_{e_{0}, \ldots, e_{i-1}, \frac{r}{2}-1, e_{i+1}, \ldots, e_{m-1}}
$$

são idênticos aos elementos correspondentes da segunda matriz da forma

$$
t_{e_{0}, \ldots, \epsilon_{i-1}, 0, e_{i+1}, \ldots, e_{m-1}}
$$

por causa da inversão dos índices na posição $i$. Devido aos bits concatenados a estas submatrizes (respectivamente $d_{0}, \ldots, d_{i-1}, 0, d_{i+1}, \ldots, d_{m-1}$ e $d_{0}, \ldots, d_{i-1}, 1, d_{i+1}, \ldots, d_{m-1}$ ). estes elementos correspondentes são adjacentes, pois eles diferem em exatamente um bit.

Provamos então que o teorema é válido para $T(r, m)$. 
Pelo que foi visto temos imediatamente o seguinte corolário.

Corolário 3.3.1 Se os nós de um n-cubo binário estão dispostos conforme $T(r, m)$, então todos os subcubos, formados pelos nós com os mesmos primeiros $k m$ bits, para $1 \leq k<\log r$, estão dispostos em $m$-cubos $\left(r / 2^{k}\right)$-ários.

\subsubsection{Método do código de Gray}

Inicialmente, definiremos o que é o código de Gray e uma maneira que ele pode ser gerado.

O código de Gray $n$-bit é representado por uma seqüência de todos os números binários de $n$ bits, tal que quaisquer dois números sucessivos diferem em somente uma posição de bit [SS88].

O código de Gray pode ser gerado de diversas maneiras, mas o melhor método é o do código de Gray refletido, que pode ser descrito do seguinte modo.

Vamos iniciar com uma seqüência de dois números de um bit, 0 e 1, a qual corresponde ao código de Gray 1-bit. Para construirmos o código de Gray 2-bit, tomamos a mesma seqüência e colocamos um bit 0 no início de cada número, então consideramos a seqüência inicial na ordem reversa e acrescentamos um bit 1 no início de cada número. Assim, temos a seqüência:

$$
G_{2}=\{00,01,11,10\}
$$

Repetimos o processo para construir o código de Gray 3-bit, tomando a sequêencia acima e inserindo o bit 0 no início de cada número, e tomando a seqüência reversa correspondente e inserindo o bit 1 no início de cada número.

$$
G_{3}=\{000,001,011,010,110,111,101,100\} .
$$

Definindo $G_{i}^{R}$ como sendo a seqüência reversa de $G_{i}$ e $0 G_{i}$ (ou. $1 G_{i}$ ) a seqüência obtida pela inserção do bit 0 (resp., o bit 1 ) no início de cada número da seqüência $G_{i}$, então o código de Gray $n$-bit pode ser gerado pela seguinte recursão:

$$
G_{n}=\left\{0 G_{n-1}, 1 G_{n-1}^{R}\right\}
$$


$\mathrm{O}$ código de Gray permite o mapeamento de grades de $d$-dimensão, $\left[a_{1} \times a_{2} \times \ldots \times a_{d}\right]$, em um $n$-cubo binário, onde $n=\left\lceil\log a_{1}\right\rceil+\left\lceil\log a_{2}\right\rceil+\ldots+\left\lceil\log a_{d}\right\rceil$. Podemos observar que o $m$-cubo $r$-ário é um caso particular de uma família de grade de dimensão $d$ descrita anteriormente.

Vamos considerar uma grade $[8 \times 4]$, isto é, $d=2, n=\lceil\log 8\rceil+\lceil\log 4\rceil=3+2=5$. Um rótulo $A$ de um nó qualquer do 5 -cubo pode ser considerado como se consistisse de duas partes: seus 3 primeiros bits e seus 2 últimos bits, podemos escrevê-lo da seguinte forma:

$$
A=b_{1} b_{2} b_{3} c_{1} c_{2}
$$

onde $b_{i}$ e $c_{j}$ são bits 0 ou 1.

Escolhendo o código de Gray 3-bit para a direção $x$ e o código de Gray 2-bit para direção $y$, ao ponto $\left(x_{i}, y_{j}\right)$ da grade é atribuído o nó $b_{1} b_{2} b_{3} c_{1} c_{2}$, onde $b_{1} b_{2} b_{3}$ é o código de Gray 3-bit para $x_{i}$ e $c_{1} c_{2}$ é o código de Gray 2-bit para $y_{j}$. O mapeamento está ilustrado na Figura 3.5. onde o número binário do nó de qualquer ponto da grade é obtido pela concatenação da coordenada binária $x$ com a coordenada binária $y$.

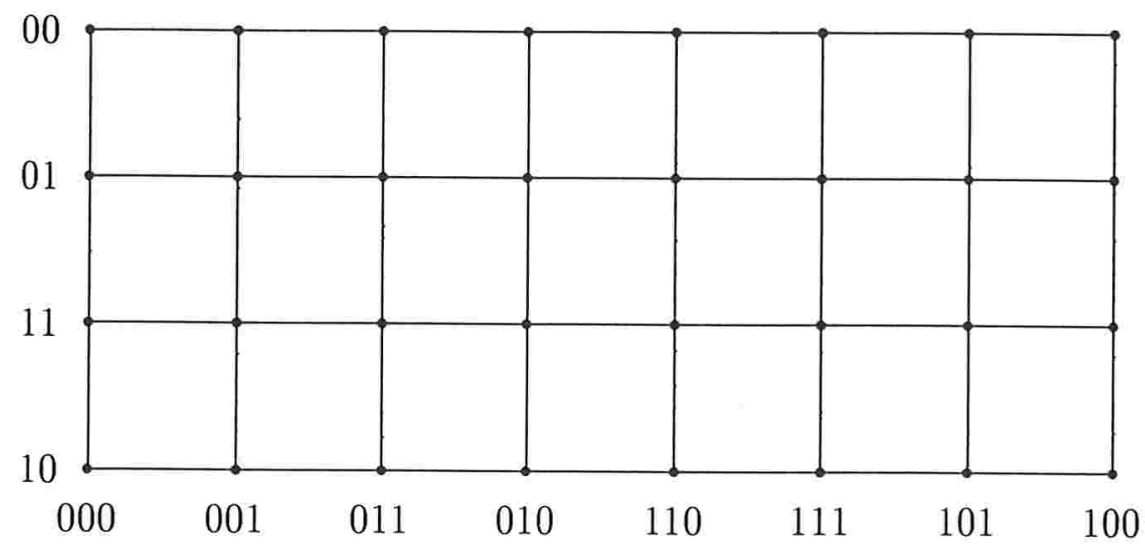

Figura 3.5: código Gray 2-D para uma grade $[8 \times 4]$.

Uma subseqüência de um código de Gray é chamada de seqüência de Gray, podemos notar que qualquer coluna de pontos da grade forma uma sequiência de Gray, assim como qualquer linha de pontos da grade. Portanto, chamaremos o código gerado acima como código de Gray 2-D.

Generalizando, uma grade de dimensão $d,\left[a_{1} \times a_{2} \times \ldots \times a_{d}\right]$, pode ser imersa em um $n$-cubo binário, onde $n=\left\lceil\log a_{1}\right\rceil+\left\lceil\log a_{2}\right\rceil+\ldots+\left\lceil\log a_{d}\right\rceil$. A numeração dos nós da grade é uma numeração qualquer, tal que sua restrição para cada $i$-ésima variável seja uma seqüência de Gray. 


\subsection{Diferença entre os dois métodos}

O método do dobramento recursivo possui uma característica importante em relação ao método de código de Gray:

Após aplicar o método do dobramento recursivo, todos os subcubos formados pelos nós quando os primeiros $\mathrm{km}$ bits são mantidos constantes, para $1 \leq k<\log r$, também estão dispostos em $m$-cubos $\left(r / 2^{k}\right)$-ários.

Vamos ilustrar isso através do caso da imersão do 2-cubo 8-ário no hipercubo. $\mathrm{O}$ mapeamento $T(8,2)$ arranja os nós como se segue:

\begin{tabular}{|llllllll|}
\hline 000000 & 000001 & 000101 & 000100 & 010100 & 010101 & 010001 & 010000 \\
000010 & 000011 & 000111 & 000110 & 010110 & 010111 & 010011 & 010010 \\
001010 & 001011 & 001111 & 001110 & 011110 & 011111 & 011011 & 011010 \\
001000 & 001001 & 001101 & 001100 & 011100 & 011101 & 011001 & 011000 \\
101000 & 101001 & 101101 & 101100 & 111100 & 111101 & 111001 & 111000 \\
101010 & 101011 & 101111 & 101110 & 111110 & 111111 & 111011 & 111010 \\
100010 & 100011 & 100111 & 100110 & 110110 & 110111 & 110011 & 110010 \\
100000 & 100001 & 100101 & 100100 & 110100 & 110101 & 110001 & 110000 \\
\hline
\end{tabular}

Vamos fixar os primeiros dois bits $(k=1)$, por exemplo em 01 . Então os nós resultantes que iniciam com 01 estão arranjados como um 2-cubo 4-ário, correspondente ao quadrante superior direito da figura acima, conforme ilustrado abaixo:

\begin{tabular}{|llll|}
\hline 010100 & 010101 & 010001 & 010000 \\
010110 & 010111 & 010011 & 010010 \\
011110 & 011111 & 011011 & 011010 \\
011100 & 011101 & 011001 & 011000 \\
\hline
\end{tabular}

Se fixarmos agora os primeiros quatro bits $(k=2)$, digamos em 0101 , então de novo os nós resultantes que iniciam com 0101 estão arranjados como um 2-cubo 2-ário (binário), conforme a figura seguinte:

\begin{tabular}{ll|}
010100 & 010101 \\
010110 & 010111 \\
\hline
\end{tabular}

Agora, vamos mostrar que o método de código de Gray não possui esta propriedade.

Para o caso do 2-cubo 8-ário, o método de código de Gray arranja os nós do hipercubo como se segue (em que os primeiros 3 bits de cada nó constituem-se numa sequência de Gray, assim como os últimos 3 bits). 


\begin{tabular}{c|cccccccc|} 
& 000 & 001 & 011 & 010 & 110 & 111 & 101 & 100 \\
\hline 000 & 000000 & 000001 & 000011 & 000010 & 000110 & 000111 & 000101 & 000100 \\
001 & 001000 & 001001 & 001011 & 001010 & 001110 & 001111 & 001101 & 001100 \\
011 & 011000 & 011001 & 011011 & 011010 & 011110 & 011111 & 011101 & 011100 \\
010 & 010000 & 010001 & 010011 & 010010 & 010110 & 010111 & 010101 & 010100 \\
110 & 110000 & 110001 & 110011 & 110010 & 110110 & 110111 & 110101 & 110100 \\
111 & 111000 & 111001 & 111011 & 111010 & 111110 & 11111 & 111101 & 111100 \\
101 & 101000 & 101001 & 101011 & 101010 & 101110 & 101111 & 101101 & 101100 \\
100 & 100000 & 100001 & 100011 & 100010 & 100110 & 100111 & 100101 & 100100 \\
\hline
\end{tabular}

Vamos agora fixar os dois primeiros bits, digamos em 01 conforme feito antes. Note-se que isso gera o seguinte.

\begin{tabular}{|llllllll|}
\hline 011000 & 011001 & 011011 & 011010 & 011110 & 011111 & 011101 & 011100 \\
010000 & 010001 & 010011 & 010010 & 010110 & 010111 & 010101 & 010100 \\
\hline
\end{tabular}

Não se obtém portanto um subcubo menor (isto é, um 2-cubo 4-ário como antes).

Caso fixarmos os primeiros quatro bits, digamos em 0101 como antes, obteríamos:

$\begin{array}{llll}010110 & 010111 & 010101 & 010100\end{array}$




\section{Capítulo 4}

\section{Utilidade do método do dobramento recursivo}

A imersão de uma rede de interconexão em uma outra é muito importante no projeto e análise de algoritmos. Através de uma imersão, algoritmos projetados originalmente para uma arquitetura podem ser diretamente mapeados para outra arquitetura.

O método de imersão do dobramento recursivo possibilita a identificação imediata de todos os subcubos menores de um $m$-cubo $r$-ário. Assim, este método pode ser muito útil para implementar algoritmos propostos para um $m$-cubo $r$-ário que necessitem de todos os subcubos menores.

Trabalhos anteriores preocuparam-se em apontar a propriedade sem, no entanto, apresentar exemplos que ilustrem a aplicabilidade e utilidade desta propriedade. Neste trabalho, apresentamos três algoritmos recursivos propostos para um $m$-cubo $r$-ário que necessitam de todos os subcubos menores. Assim, se implementarmos estes algoritmos no hipercubo utilizando a disposição $T(r, m)$, podemos obter de maneira fácil os endereços destes subcubos através da mencionada propriedacle.

Na seção 4.1, apresentaremos os algoritmos recursivos de transposição de matriz, multiplicação de matrizes e ordenação por intercalação Par-Ímpar. Estes algoritmos foram projetados para um $m$-cubo $r$-ário e apresentam a característica citada acima.

\subsection{Utilização da propriedade}

O objetivo deste trabalho é mostrar que a propriedade apontada acima pode ser útil para utilização de algoritmos do tipo divisão-e-conquista projetados para um $m$-cubo $r$-ário no 
hipercubo através da técnica de imersão do dobramento recursivo.

Considere um algoritmo recursivo para uma determinada aplicação projetado para um $m$-cubo $r$-ário e que necessite de todos os subcubos menores. $\mathrm{Na}$ implementação do algoritmo precisamos identificar de maneira fácil todos os subcubos menores. O método do dobramento recursivo permite a obtenção imediata dos endereços desses subcubos menores conforme visto anteriormente.

Mostraremos nesta seção que o método do dobramento recursivo pode ser útil para classe de problemas matriciais do tipo divisão-e-conquista. Para ilustrar isso, utilizaremos três algoritmos recursivos:

- Transposição de Matriz,

- Multiplicação de Matrizes e

- Ordenação por Intercalação Par-Ímpar.

\subsubsection{Transposição de matriz}

A transposta de uma matriz $A=\left(a_{i j}\right), n \times n$, é uma matriz $A^{T}=\left(a_{i j}^{T}\right)$ de mesmo tamanho, tal que $a_{i j}^{T}=a_{j i}$, para $0 \leq i, j<n$, isto é, as linhas de $A^{T}$ são as colunas de $A$. No processo de transposição de matriz, todos elementos abaixo da diagonal principal são deslocados para posições simétricas (em relação à diagonal principal) acima da diagonal principal e vice-versa.

Seja $A$ uma matriz quadrada $n \times n$ :

$$
A=\left[\begin{array}{ll}
A_{0,0} & A_{0,1} \\
A_{1,0} & A_{1,1}
\end{array}\right],
$$

onde $A_{i, j}$ são submatrizes $\frac{n}{2} \times \frac{n}{2}$. Podemos calcular a transposta da matriz $A$ trocando inicialmente os elementos correspondentes das submatrizes $A_{0,1}$ e $A_{1,0}$ entre si, conforme a Figura 4.1, e então transpondo recursivamente e em paralelo os elementos dentro de cada submatriz $A_{i, j}$. Este algoritmo foi baseado no texto de Kumar et al. [KGGK94].

Supomos que a matriz $A$ esteja armazenada em uma grade $[n \times n]$, ou seja, 2-cubo $n$-ário, de modo que cada processador armazene um único elemento da matriz. Supomos que $n$ é uma potência de 2 .

Baseado na descrição acima, temos um algoritmo recursivo chamado Transposta (Algoritmo 4.1.1) que, dados uma matriz $A$, a ordem $n$ desta matriz e a coordenada $(x, y)$ 


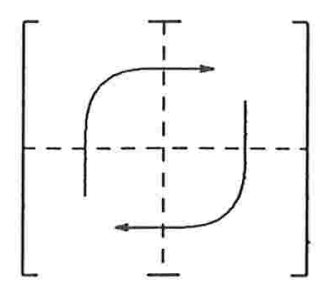

Figura 4.1: $A_{0,1} \longleftrightarrow A_{1,0}$.

do elemento que se encontra no canto superior esquerdo (veja a Figura 4.2), obtemos a matriz transposta de $A, A^{T}$. Assim, a primeira chamada deste algoritmo deve ser o seguinte: Transposta $(A, n, 0,0)$.

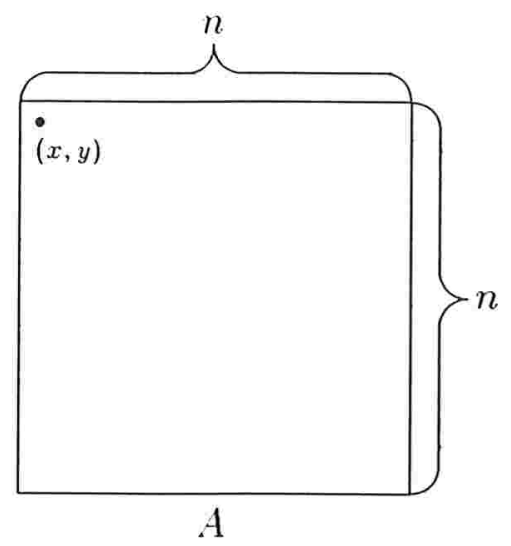

Figura 4.2: Entrada do Algoritmo 4.1.1.

Algoritmo 4.1.1 Entrada:

- uma matriz A,

- $a$ ordem de $A, n$ e

- a coordenada do canto superior esquerdo da matriz $A,(x, y)$;

Saída:

A matriz transposta de $A, A^{T}$.

Transposta $(A, n, x, y)$

begin

if $n \neq 1$ then begin 
$\operatorname{Troca}\left(A, \frac{n}{2}, x, y+\frac{n}{2}, x+\frac{n}{2}, y\right)$

parbegin

Transposta $\left(A, \frac{n}{2}, x, y\right)$;

Transposta $\left(A, \frac{n}{2}, x, y+\frac{n}{2}\right)$;

Transposta $\left(A, \frac{n}{2}, x+\frac{n}{2}, y\right)$;

parend

Transposta $\left(A, \frac{n}{2}, x+\frac{n}{2}, y+\frac{n}{2}\right)$

end

end

Os comandos (separados por ;) colocados entre parbegin e parend são executados em paralelo.

O algoritmo Transposta, por sua vez, faz a chamada do procedimento Troca, Algoritmo 4.1.2. Este procedimento executa a troca dos elementos da submatriz do segundo quadrante (quadrante superior direito) pelos do terceiro quadrante (quadrante inferior esquerdo), Figura 4.1. Como entrada deste procedimento temos a matriz $A$, a ordem $m$ das submatrizes em questão, as coordenadas do canto superior esquerdo do segundo e do terceiro quadrantes, respectivamente $\left(\operatorname{seg}_{x}, \operatorname{seg}_{y}\right)$ e $\left(\operatorname{ter} c_{x}, \operatorname{ter} c_{y}\right)$. Veja Figura 4.3.

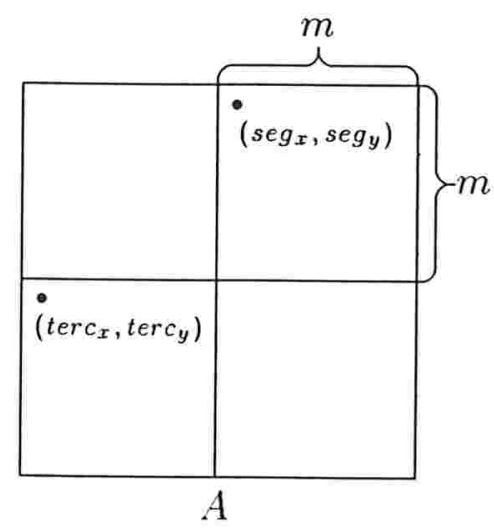

Figura 4.3: Entrada do Algoritmo 4.1.2.

\section{Algoritmo 4.1.2 Entrada:}

- a matriz $A$,

- a ordem das submatrizes em questão, $m$,

- a coordenada do canto superior esquerdo da submatriz que se encontra no segundo quadrante, $\operatorname{seg}_{x}$ e $\operatorname{seg}_{y} e$ 
- a coordenada do canto superior esquerdo do terceiro quadrante, terc $c_{x}$ e terc $c_{y}$;

Saída: A troca entre os elementos correspondentes do segundo e terceiro quadrantes.

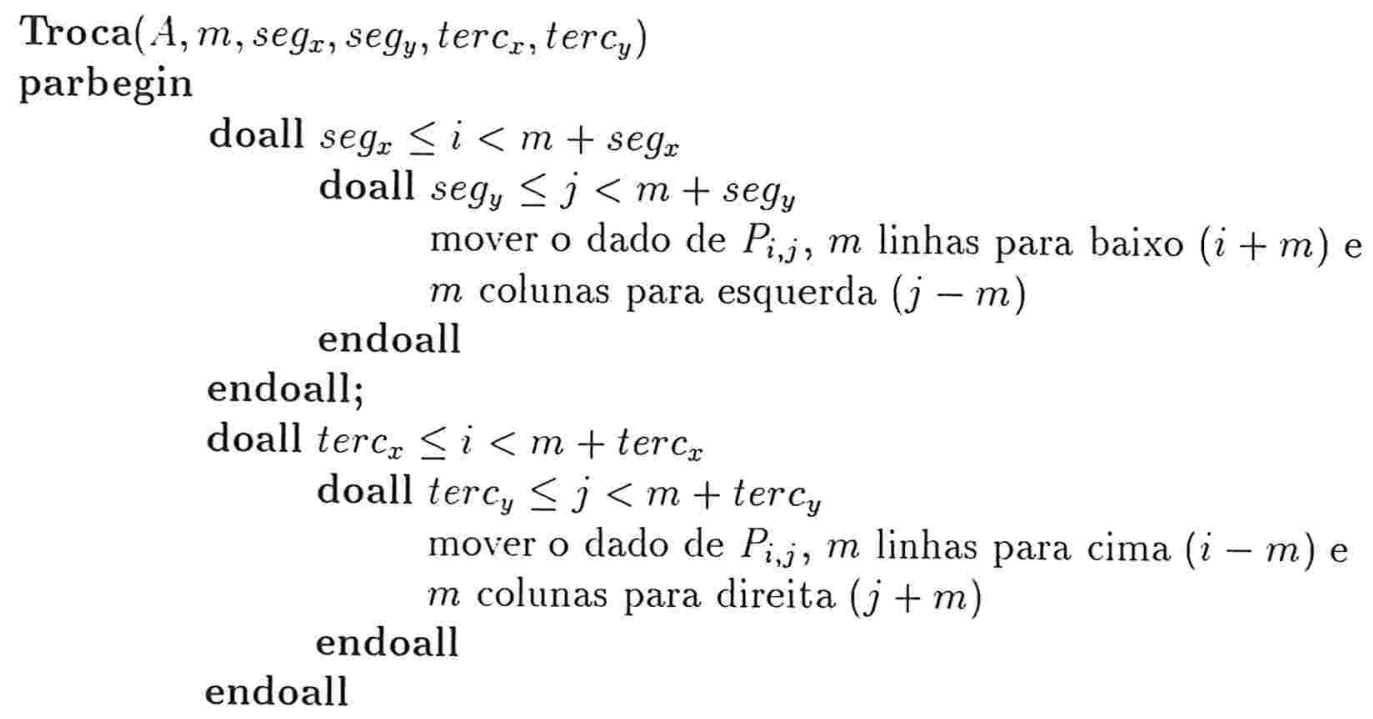

parend

Usamos doall para indicar laços sem dependência entre iterações permitindo a execução de todas as iterações em paralelo.

O movimento dos dados nos dois doall's acima deve ser feito de modo síncrono. ra 4.4

O algoritmo de transposição recursivo para uma matriz $S \times \&$ está ilustrado na Figu-

\subsubsection{Multiplicação de matrizes}

Dadas duas matrizes quadradas $A$ e $B$ de ordem $n$, onde $A=\left(a_{i j}\right)$ e $B=\left(b_{i j}\right)$, para $0 \leq i, j<n$, deseja-se calcular a matriz produto $C=A \times B$, onde $C=\left(c_{i j}\right)$, tal que $c_{i j}=\sum_{k=0}^{n-1} a_{i k} \times b_{k j}$.

Sejam $A, B$ e $C$ matrizes quadradas de ordem $n \times n$, com $n$ potência de 2 :

$$
A=\left[\begin{array}{ll}
A_{0,0} & A_{0,1} \\
A_{1,0} & A_{1,1}
\end{array}\right], B=\left[\begin{array}{ll}
B_{0,0} & B_{0,1} \\
B_{1,0} & B_{1,1}
\end{array}\right], C=\left[\begin{array}{ll}
C_{0,0} & C_{0,1} \\
C_{1,0} & C_{1,1}
\end{array}\right],
$$

onde $A_{i, j}, B_{i, j}, C_{i, j}$ são submatrizes $\frac{n}{2} \times \frac{n}{2}$. 


\begin{tabular}{|c|c|c|c|c|c|c|c|}
\hline$(0,0)$ & $(0,1)$ & $(0,2)$ & $(0,3)$ & $(0,4)$ & $(0,5)$ & $(0,6)$ & $(0,7)$ \\
\hline$(1,0)$ & $(1,1)$ & $(1,2)$ & $(1,3)$ & $(1,4)$ & $(1,5)$ & $(1,6)$ & $(1,7)$ \\
\hline$(2,0)$ & $(2,1)$ & $(2,2)$ & $(2,3)$ & $(2,4)$ & $(2,5)$ & $(2,6)$ & $(2,7)$ \\
\hline$(3,0)$ & $(3,1)$ & $(3,2)$ & $(3,3)$ & $(3,4)$ & $(3,5)$ & $(3,6)$ & $(3,7)$ \\
\hline$(4,0)$ & $(4,1)$ & $(4,2)$ & $(4,3)$ & $(4,4)$ & $(4,5)$ & $(4,6)$ & $(4,7)$ \\
\hline$(5,0)$ & $(5,1)$ & $(5,2)$ & $(5,3)$ & $(5,4)$ & $(5,5)$ & $(5,6)$ & $(5,7)$ \\
\hline$(6,0)$ & $(6,1)$ & $(6,2)$ & $(6,3)$ & $(6,4)$ & $(6,5)$ & $(6,6)$ & $(6,7)$ \\
\hline$(7,0)$ & $(7,1)$ & $(7,2)$ & $(7,3)$ & $(7,4)$ & $(7,5)$ & $(7,6)$ & $(7,7)$ \\
\hline
\end{tabular}

(a)

\begin{tabular}{|c|c|c|c|c|c|c|c|}
\hline$(0,0)$ & $(0,1)$ & \begin{tabular}{c}
$(2,0)$ \\
\hdashline
\end{tabular} & $>(2,1)$ & $(4,0)$ & $=(4,1)$ & $(6,0)$ & 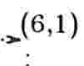 \\
\hline$(1,0)$ & $(1,1)$ & $(3,0)$ & $(3,1)$ & $(5,0)^{<}$ & $(5,1)$ & $(7,0)$ & $(7,1)$ \\
\hline$(0,2)$ & $(0,3)$ & $(2,2)$ & $(2,3)$ & $(4,2)$ & $>(4,3)$ & $(6,2)$ & $(6,3)$ \\
\hline$(1,2)$ & $(1,3)$ & $(3,2)$ & $(3,3)$ & $(5,2)^{<}$ & $(5,3)$ & $(7,2)$ & $(7,3)$ \\
\hline$(0,4)$ & $(0,5)$ & $(2,4)$. & $(2,5)$ & $(4,4)$ &,$(4,5)$ & $(6,4)$ & $>(6,5)$ \\
\hline$(1,4)$ & $(1,5)$ & $(3,4)$ & $(3,5)$ & $(5,4)$ & $(5,5)$ & $(7,4)^{2}$ & $(7,5)$ \\
\hline$(0,6)$ & $(0,7)$ & $(2,6)$ & $(2,7)$ & $(4,6)$ & $(4,7)$ & $(6,6)$ & $(6,7)$ \\
\hline$(1,6)$ & $(1,7)$ & $(3,6)$ & $(3,7)$ & $(5,6)^{<}$ & $(5, \pi)$ & $(7,6)$ & $(7,7)$ \\
\hline
\end{tabular}

(c)

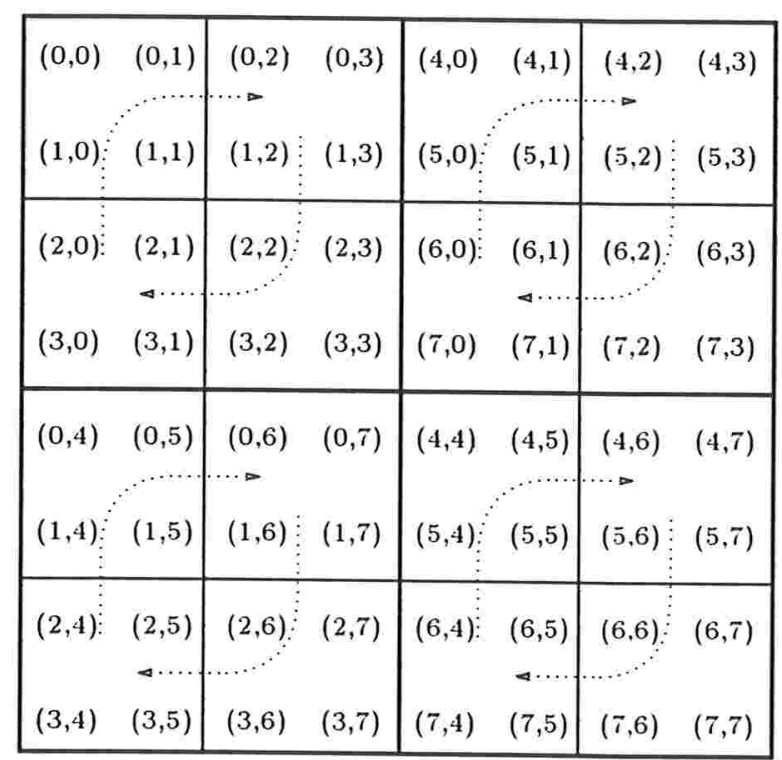

(b)

\begin{tabular}{|lllllllll|}
\hline$(0,0)$ & $(1,0)$ & $(2,0)$ & $(3,0)$ & $(4,0)$ & $(5,0)$ & $(6,0)$ & $(7,0)$ \\
$(0,1)$ & $(1,1)$ & $(2,1)$ & $(3,1)$ & $(4,1)$ & $(5,1)$ & $(6,1)$ & $(7,1)$ \\
$(0,2)$ & $(1,2)$ & $(2,2)$ & $(3,2)$ & $(4,2)$ & $(5,2)$ & $(6,2)$ & $(7,2)$ \\
$(0,3)$ & $(1,3)$ & $(2,3)$ & $(3,3)$ & $(4,3)$ & $(5,3)$ & $(6,3)$ & $(7,3)$ \\
$(0,4)$ & $(1,4)$ & $(2,4)$ & $(3,4)$ & $(4,4)$ & $(5,4)$ & $(6,4)$ & $(7,4)$ \\
$(0,5)$ & $(1,5)$ & $(2,5)$ & $(3,5)$ & $(4,5)$ & $(5,5)$ & $(6,5)$ & $(7,5)$ \\
$(0,6)$ & $(1,6)$ & $(2,6)$ & $(3,6)$ & $(4,6)$ & $(5,6)$ & $(6,6)$ & $(7,6)$ \\
$(0,7)$ & $(1,7)$ & $(2,7)$ & $(3,7)$ & $(4,7)$ & $(5,7)$ & $(6,7)$ & $(7,7)$ \\
\hline
\end{tabular}

(d)

Figura 4.4: Transposição de uma matriz $8 \times 8$. 
Queremos multiplicar as matrizes $A$ e $B$ e o resultado desta operação seja armazenado na matriz $C$, isto é, $C=A \times B$. Assim, temos que:

$$
\begin{aligned}
& C_{0,0}=A_{0,0} B_{0,0}+A_{0,1} B_{1,0}, \\
& C_{0,1}=A_{0,0} B_{0,1}+A_{0,1} B_{1,1}, \\
& C_{1,0}=A_{1,0} B_{0,0}+A_{1,1} B_{1,0}, \\
& C_{1,1}=A_{1,0} B_{0,1}+A_{1,1} B_{1,1} .
\end{aligned}
$$

Considere que as matrizes $A$ e $B$ estão arranjadas em uma grade $P=[n \times n]$, como mostra a Figura 4.5.

Inicialmente, suponhamos que cada processador $p_{i, j}$ de $P$ armazene os elementos $a_{i, j}$ e $b_{i, j}, 0 \leq i, j<n$.

\begin{tabular}{|l|l|}
\hline$A_{0,0} B_{0,0}$ & $A_{0,1} B_{0,1}$ \\
\hline & \\
$A_{1,0} B_{1,0}$ & $A_{1,1} B_{1,1}$ \\
\hline
\end{tabular}

Figura 4.5: Disposição das matrizes $A$ e $B$ na grade

Podemos descrever o algoritmo de multiplicação de matrizes nos seguintes passos [San92]. Primeiramente, trocamos as submatrizes $B_{0,1}$ e $B_{1,0}$ de lugar, conforme a Figura 4.6. $B_{0,1}$, isto é, os elementos da matriz $B$ que se encontram na submatriz do quadrante superior direito, desliza para o canto inferior direito, enquanto $B_{1,0}$, elementos de $B$ que estão no quadrante inferior esquerdo, desliza para o canto superior esquerdo. Então, $B_{0,1}$ desliza para o quadrante inferior esquerdo, enquanto $B_{1,0}$ desliza para o quadrante superior direito. Para executarmos este passo é necessário a utilização de registradores extras.

No próximo passo, aplicamos o algoritmo de multiplicação de matrizes simultaneamente entre as submatrizes de $A$ e $B$ que se encontram armazenadas em cada um dos quadrantes.

A seguir, devemos transferir e somar os resultados obtidos no passo anterior, de acordo com a Figura 4.7 , a fim de calcular $C_{0,0}$ e $C_{1,1}$. 

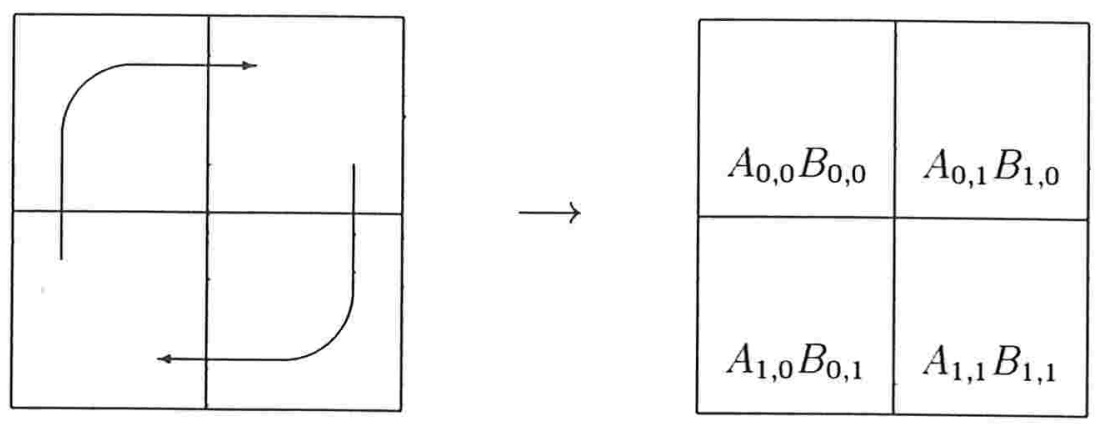

Figura 4.6: $B_{0,1} \leftrightarrow B_{1,0}$

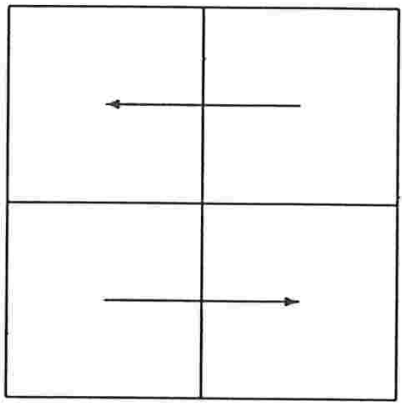

$\longrightarrow \quad$\begin{tabular}{c|c|}
\hline$C_{0,0}$ & \\
$A_{0,0} B_{0,0}$ & $A_{0,1} B_{1,0}$ \\
\hline & $C_{1,1}$ \\
$A_{1,0} B_{0,1}$ & $A_{1,1} B_{1,1}$ \\
\hline
\end{tabular}

Figura 4.7: Cálculo de $C_{0,0}$ e $C_{1,1}$

No passo da Figura 4.8, devemos fazer a troca entre as submatrizes $B_{0,0}$ e $B_{0,1}$ concorrentemente à troca de $B_{1,1}$ e $B_{1,0}$. E assim, calculamos simultaneamente os produtos de cada submatriz de $A$ e $B$ contidas no mesmo quadrante, aplicando recursivamente o algoritmo de multiplicação de matrizes.
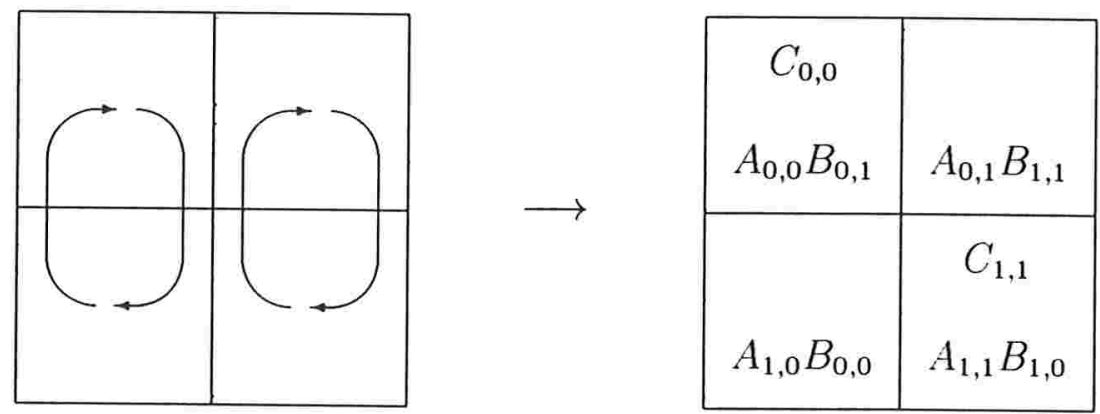

Figura 4.8: $B_{0,0} \leftrightarrow B_{0,1}$ e $B_{1,1} \leftrightarrow B_{1,0}$

Finalmente, transferimos e somamos os resultados obtidos no passo anterior, de acordo com a Figura 4.9, para calcular $C_{0,1}$ e $C_{1,0}$.

Para que as submatrizes $A$ e $B$ fiquem em suas posições originais, basta fazer alguns 


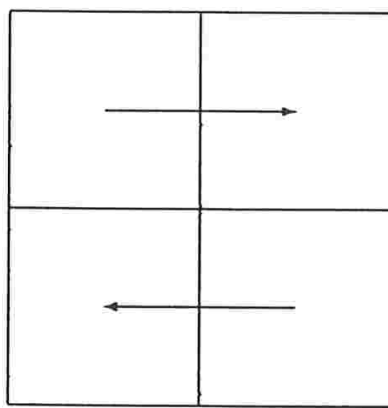

$\longrightarrow \quad$\begin{tabular}{c|c|}
\hline$C_{0,0}$ & $C_{0,1}$ \\
$A_{0,0} B_{0,1}$ & $A_{0,1} B_{1,1}$ \\
\hline$C_{1,0}$ & $C_{1,1}$ \\
$A_{1,0} B_{0,0}$ & $A_{1,1} B_{1,0}$ \\
\hline
\end{tabular}

Figura 4.9: Cálculo de $C_{0,1}$ e $C_{1,0}$

roteamentos.

\subsubsection{Ordenação por intercalação Par-Ímpar}

Este algoritmo de ordenação por intercalação Par-Ímpar em grades quadradas foi proposto por Ullman [Ull83]. Inicialmente, apresentaremos o algoritmo de ordenação Par-Ímpar para listas lineares proposto por Batcher.

\section{Algoritmo de ordenação por intercalação Par-Ímpar}

Originalmente, este algoritmo foi descrito como uma rede de comparadores de tamanho $O\left(n \log ^{2} n\right)$ para ordenar $n$ elementos em tempo $O\left(\log ^{2} n\right)$ [Bat68, Knu73]. Entretanto, o algoritmo também pode ser usado como um procedimento de ordenação em uma máquina paralela. Neste caso, haverá, em geral, menos processadores que o número de elementos na entrada.

Uma ordenação por intercalação (merge) é baseada na seguinte idéia: particionamos uma lista de $2 n$ elementos em duas sublistas de comprimento $n$, ordenamo-las recursivamente e então intercalamos estas listas já ordenadas.

Consideremos duas listas ordenadas de $n$ números ( $n$ é uma potência de 2), $A$ : $a_{1}, \ldots, a_{n}$ e $B: b_{1}, \ldots, b_{n}, a_{i} \leq a_{i+1}$ e $b_{i} \leq b_{i+1}$ para todo $1 \leq i<n$. Queremos intercalar estes números em uma lista ordenada $L$ de tamanho $2 n$. Um modo para fazer isto é utilizando um algoritmo recursivo chamado Par-Ímpar.

Se $n=1$, então basta colocar $a_{1}$ e $b_{1}$ em ordem crescente. Para intercalar $A$ e $B$, primeiro particionamo-las em sublistas com os elementos que ocupam as posições ímpares e pares, isto é: 


$\begin{array}{llll}A_{\text {impar }}: a_{1}, a_{3}, \ldots, a_{n-1} & A_{\text {par }}: a_{2}, a_{4}, \ldots, a_{n} \\ B_{\text {impar }}: & b_{1}, b_{3}, \ldots, b_{n-1} & B_{\text {par }}: & b_{2}, b_{4}, \ldots, a_{n}\end{array}$

Observe que estas sublistas também estão ordenadas, uma vez que $A$ e $B$ estavam ordenadas.

A seguir, intercalamos recursivamente $A_{\text {impar }}$ com $B_{\text {impar }}$ a fim de formar uma lista ordenada $C$ e $A$ par com $B$ par para formar uma outra lista ordenada $D$. À primeira vista, parece que a formação de $C$ e $D$ não traz algum progresso desde que temos ainda que intercalá-las para obter $L$. Entretanto, a tarefa de intercalar $C$ e $D$ é muito mais fácil que a tarefa de intercalar $A$ e $B$. Particularmente, $C=c_{1}, \ldots, c_{n}$ e $D=d_{1}, \ldots, d_{n}$ podem ser intercaladas da seguinte maneira. Primeiro construímos:

$$
L^{\prime}=c_{1}, d_{1}, c_{2}, d_{2}, \ldots, c_{n}, d_{n}
$$

então comparamos cada $c_{i}$ com $d_{i-1}, i \geq 2$ e trocamo-los se eles estiverem fora de ordem. A lista resultante está ordenada. Isto pode ser formalizado no seguinte lema [Ull83].

Lema 4.1.1 Considere que $A: a_{1}, \ldots, a_{n}$ e $B: b_{1}, \ldots, b_{n}$ são listas ordenadas, $C$ : $c_{1}, \ldots, c_{n}$ é a lista ordenada obtida da intercalação de $A_{\text {ímpar }}: a_{1}, a_{3}, \ldots, a_{n-1}$ com $B_{\text {impar }}: b_{1}, b_{3}, \ldots, b_{n-1}$ e $D: d_{1}, \ldots, d_{n}$ é a lista ordenada obtida da intercalação de Apar : $a_{2}, a_{4}, \ldots, a_{n}$ com Bpar: $b_{2}, b_{4}, \ldots, b_{n}$. Então os números $a_{1}, \ldots, a_{n}, b_{1}, \ldots, b_{n}$ podem ser encontrados em uma seqüência ordenada pelos seguintes passos:

1. Embaralhar $C: c_{1}, \ldots, c_{n}$ com $D: d_{1}, \ldots, d_{n}$ para obter $L^{\prime}: c_{1}, d_{1}, c_{2}, d_{2}, \ldots, c_{n}, d_{n}$.

2. Comparar cada $c_{i}$ com $d_{i-1}$ e trocá-los entre si, se eles estiverem fora de ordem, isto é, se $d_{i-1}>c_{i}$.

\section{Prova:}

Para simplificar, supomos que todos os elementos são distintos. Certamente, se o algoritmo funciona quando os elementos são distintos, funcionará quando eles nào forem. Mostraremos que cada $c_{m}$ pertence, ou imediatamente antes, ou imediatamente depois de $d_{m-1}$ na seqüência ordenada. Sem perda de generalidade, vamos considerar que $c_{m}$ pertence à lista $A, c_{m}=a_{2 i+1}$, e entre $c_{1}, \ldots, c_{m-1}$ há exatamente $k$ elementos pertencentes à lista $B$, que devem ser $b_{1}, b_{3}, \ldots, b_{2 k-1}$. 


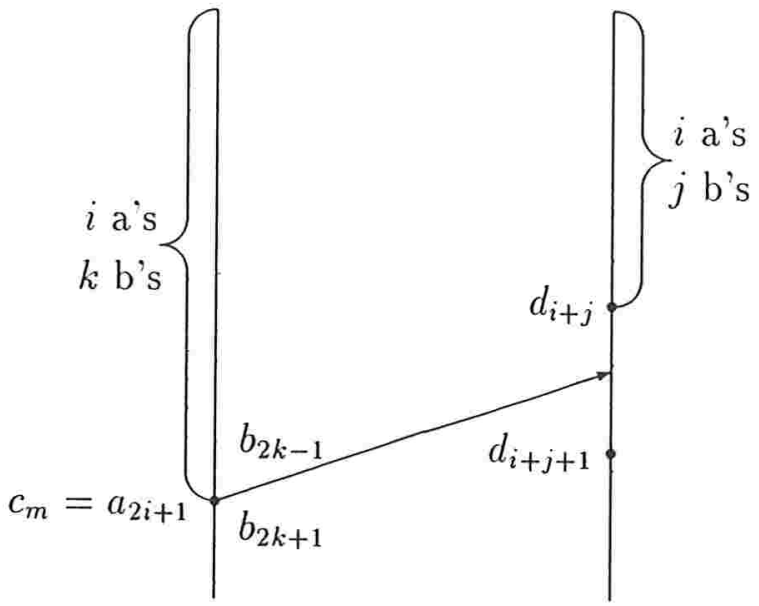

Figura 4.10: Intercalação de ímpares e pares

Vamos supor que na lista intercalada $c_{m}=a_{2 i+1}$ está entre $d_{i+j}$ e $d_{i+j+1}$, conforme Figura 4.10. Então entre os primeiros $(i+j) d$ 's deve haver exatamente $i$ a's, denotados por $a_{2}, a_{4}, \ldots, a_{2 i}$, porque eles são exatamente os $a$ 's pares que precedem $a_{2 i+1}$.

Devemos deduzir qual o valor de $j$, isto é, quantos $b$ 's pares precedem $a_{2 i+1}$. Certamente $a_{2 i+1}$ sucede pelo menos $k-1 b$ 's pares, denotados por $b_{2}, b_{4}, \ldots, b_{2 k-2}$, uma vez que $a_{2 i+1}$ sucede $b_{2 k-1}$, o qual por sua vez sucede estes $b$ 's. Contudo, $a_{2 i+1}$ não pode suceder mais que $k$ 's pares, porque $a_{2 i+1}$ precede $b_{2 k+1}$, o qual precede todos os $b$ 's pares exceto $b_{2}, b_{4}, \ldots, b_{2 k}$.

Assim, $j$ é ou $k-1$ ou $k$, visto que $m=i+k+1$, agora sabemos que $c_{m}=a_{2 i+1}$ deve ficar ou entre $d_{m-2}$ e $d_{m-1}($ se $j=k-1)$ ou entre $d_{m-1}$ e $d_{m}$ (se $j=k$ ). Assim, para decidir onde $c_{m}$ deve ficar, precisamos somente compará-lo com $d_{m-1}$.

Exemplo 4.1.1 : Considere as seguintes listas ordenadas:

$$
\begin{array}{rrrrrr}
A & : & 1 & 5 & 16 & 23 \\
B & : & 2 & 3 & 4 & 6
\end{array}
$$

Vamos particionar estas listas em sublistas impares e pares, e intercalamo-las, aplicando o algoritmo Par-Ímpar recursivamente.

$$
\begin{array}{lllr}
A_{\text {impar }}: & 1 & 16 \\
B_{\text {impar }} & : & 2 & 4
\end{array}
$$




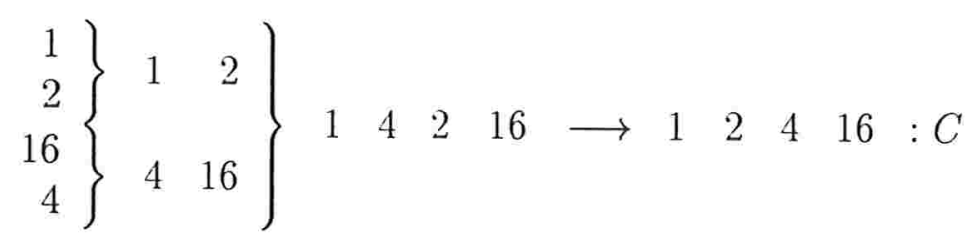

$$
\begin{array}{rrrr}
\text { Apar }: & 5 & 23 \\
\text { Bpar }: & 3 & 6
\end{array}
$$

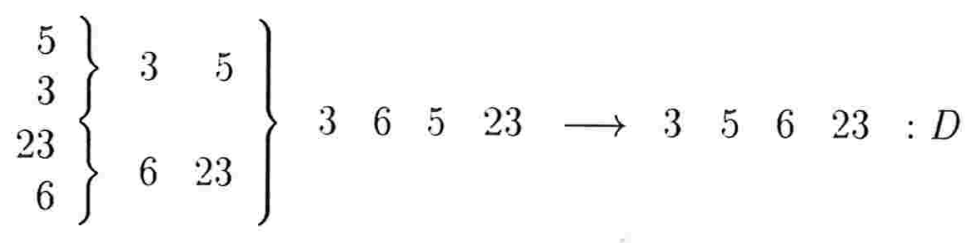

Obtendo assim as listas C e D. Agora, embaralhamos estas listas e temos:

$$
L^{\prime}=\begin{array}{llllllll}
1 & 3 & 2 & 5 & 4 & 6 & 16 & 23
\end{array}
$$

Finalmente, trocamos as posições pares com o seu próximo ímpar se eles estiverem fora de ordem. Este passo corresponde ao passo 2 do Lema 4.1.1.

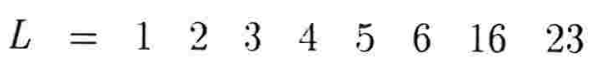

\section{Ordenação por intercalação Par-Ímpar numa grade quadrada}

Nesta seção, mostraremos como implementar o algoritmo de ordenação por intercalação Par-Ímpar de $n$ números em uma grade $\sqrt{n} \times \sqrt{n}$.

Dizemos que a grade $\sqrt{n} \times \sqrt{n}$ está ordenada quando os $\sqrt{n}$ menores elementos aparecem ordenados na primeira linha, os próximos $\sqrt{n}$ menores elementos estão na segunda linha e assim por diante.

O algoritmo recursivo de ordenação está ilustrado na Figura 4.11. A grade é dividida em quatro quadrantes menores $\left(\frac{\sqrt{n}}{2} \times \frac{\sqrt{n}}{2}\right)$, os quais são ordenados recursivamente e simultaneamente, como indicado na Figura 4.11(a).

Assim, os dois quadrantes da esquerda são intercalados por uma implementação da intercalação Par-Ímpar; ao mesmo tempo, os dois quadrantes da direita são intercalados 


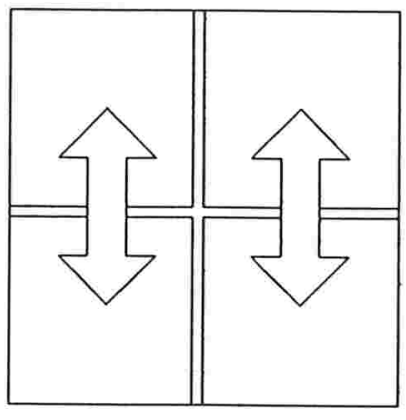

(a)

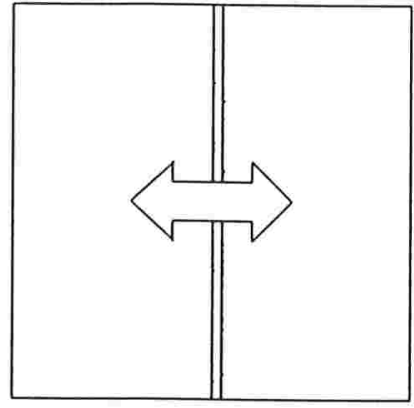

(b)

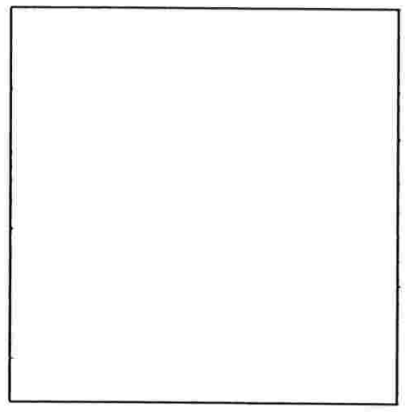

(c)

Figura 4.11: Algoritmo de ordenação recursiva

da mesma maneira, o resultado está ilustrado na Figura 4.11(b). Finalmente, os dois retângulos são intercalados de modo similar.

O passo da intercalação Par-Ímpar recursivo está ilustrado na Figura 4.12. Para partir da Figura 4.12(a) para Figura 4.12(b), separamos os elementos das posições pares dos das posições impares das listas $A$ e $B$, movendo os elementos das posições ímpares para esquerda, enquanto os pares para direita.

O passo da Figura 4.12(b) para Figura 4.12(c) é direto. $B_{\text {impar }}$, o quadrante inferior esquerdo na Figura 4.12(b), desliza para o canto superior esquerdo, enquanto $A_{\text {par }}$, o quadrante superior direito, desliza para o canto inferior direito. Naturalmente, são utilizados

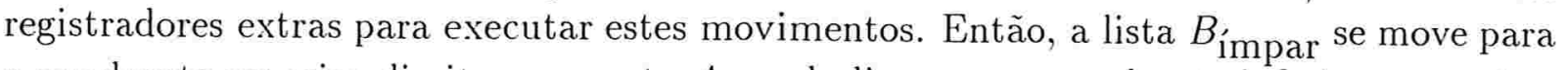
o quadrante superior direito, enquanto $A_{\text {par }}$ desliza para o quadrante inferior esquerdo. 


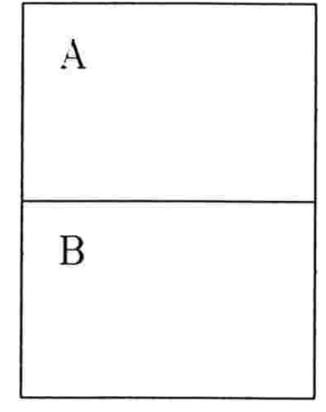

(a)

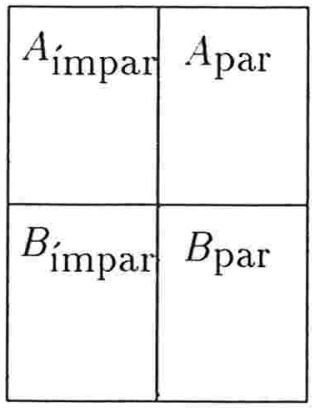

(b)

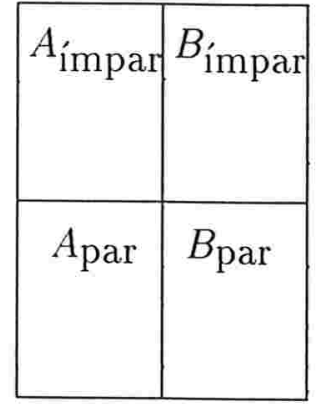

(c)

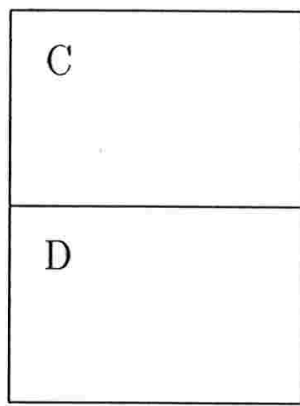

(d)

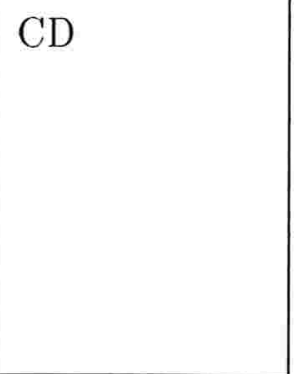

(e)

Figura 4.12: Algoritmo de intercalação Par-Ímpar

A transformação da Figura 4.12(c) para Figura 4.12(d) envolve a aplicação simultânea do algoritmo Par-Ímpar para intercalar $A_{\text {impar }}$ com $B_{\text {ímpar }}$ e $A_{\text {par com }} B_{\text {par }}$. Então para atingir o passo da Figura 4.12(e), as listas resultantes do passo anterior, $C$ e $D$ do Lema 4.1.1, são embaralhadas. Se a altura do retângulo $C D$ é igual a $2 m$, então a $i$-ésima linha de $C$ é movida $i-1$ linhas para baixo e a $i$-ésima linha de $D$ é movida para cima $m+1-i$ linhas. Então as $i$-ésimas linhas das duas sublistas, as quais estão fisicamente locadas na mesma linha de processadores, são embaralhadas e distribuídas na linha $2 i-1$ e na linha $2 i$. E então comparamos cada $c_{i}$ com $d_{i-1}$, se estiverem fora de ordem trocamo-los de lugar. 
Exemplo 4.1.2 : Considere a seguinte grade. Vamos ordená-la utilizando o algoritmo de ordenação Par-Ímpar para grades.

\begin{tabular}{|cccc|}
\hline 5 & 2 & 1 & 4 \\
16 & 7 & 12 & 14 \\
15 & 3 & 6 & 13 \\
8 & 10 & 11 & 9 \\
\hline
\end{tabular}

Inicialmente, dividimos a grade em quatro quadrantes e ordenamos estes recursivamente e concorrentemente.

\begin{tabular}{|cc||cc|}
\hline 5 & 2 & 1 & 4 \\
16 & 7 & 12 & 14 \\
\hline \hline 15 & 3 & 6 & 13 \\
8 & 10 & 11 & 9 \\
\hline
\end{tabular}

\begin{tabular}{|c|c||c|c|}
\hline 5 & 2 & 1 & 4 \\
\hline 16 & 7 & 12 & 14 \\
\hline \hline 15 & 3 & 6 & 13 \\
\hline 8 & 10 & 11 & 9 \\
\hline
\end{tabular}

Então vamos intercalar, utilizando o algoritmo Par-Ímpar, os dois quadrantes da esquerda e os dois da direita concorrentemente, passo(a) da figura 4.11.

\begin{tabular}{|cc||cc|}
\hline 2 & 5 & 1 & 4 \\
7 & 16 & 12 & 14 \\
\hline \hline 3 & 8 & 6 & 9 \\
10 & 15 & 11 & 13 \\
\hline
\end{tabular}

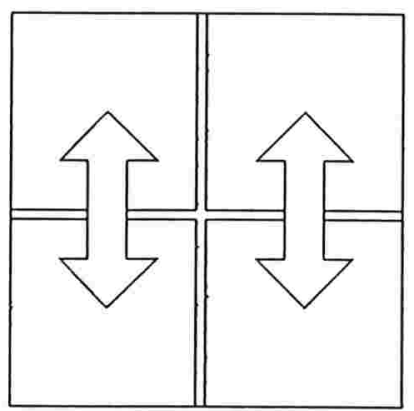


Agora, separamos os elementos das posições pares dos das ímpares e executamos o passo $(b) \longrightarrow(c)$ da figura 4.12 do algoritmo de intercalação Par-Ímpar.

\begin{tabular}{|c|c||c|c|}
\hline 2 & 5 & 1 & 4 \\
7 & 16 & 12 & 14 \\
\hline 3 & 8 & 6 & 9 \\
10 & 15 & 11 & 13 \\
\hline
\end{tabular}

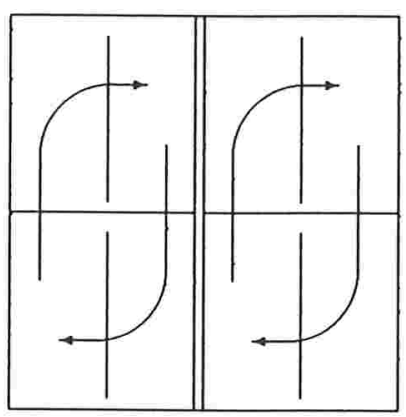

No passo seguinte, intercalarmos os elementos ímpares, ( $A_{\text {impar }} \longleftrightarrow B_{\text {impar }}$ ), e os elementos pares, (Apar $\longleftrightarrow$ Bpar), passo Figura 4.12(c) $\longrightarrow$ Figura 4.12(d).

\begin{tabular}{|c|c||c|c|}
\hline 2 & 3 & 1 & 6 \\
7 & 10 & 12 & 11 \\
\hline 5 & 8 & 4 & 9 \\
16 & 15 & 14 & 13 \\
\hline
\end{tabular}

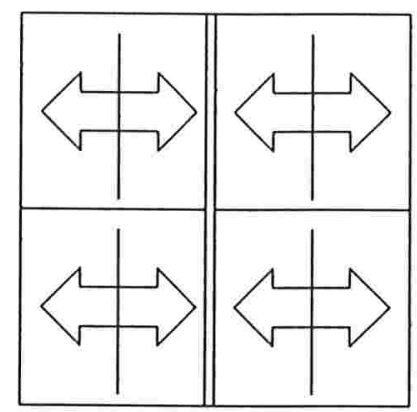

Obtemos assim as listas $C$ e D, Figura 4.12(d).

\begin{tabular}{|cc||cc|}
\hline 2 & 3 & 1 & 6 \\
7 & 10 & 11 & 12 \\
\hline 5 & 8 & 4 & 9 \\
15 & 16 & 13 & 14 \\
\hline
\end{tabular}

\begin{tabular}{|c||c|}
\hline $\mathrm{C}$ & $\mathrm{C}$ \\
\hline $\mathrm{D}$ & $\mathrm{D}$ \\
\hline
\end{tabular}


Embaralhamos os elementos das lista $C$ com os da lista $D$ e então comparamos os elementos $c_{i}$ com os $d_{i-1}$, se eles estiverem fora de ordem, trocamo-los de lugar, Figura $4.12(e)$.

\begin{tabular}{|c|c|}
\hline${ }^{2}{ }_{5}{ }^{3} \mathrm{~g}$ & $1_{4} \quad 6_{9}$ \\
\hline $15^{7} 16^{10}$ & $13^{11} 14^{12}$ \\
\hline
\end{tabular}

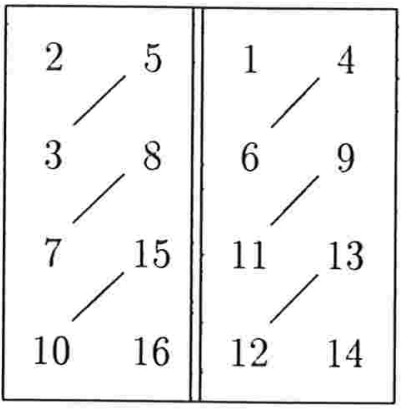

Agora executamos o passo (b) da Figura 4.11 do algoritmo de ordenação recursiva. Intercalamos os dois retângulos utilizando o algoritmo de intercalação Par-Ímpar.

\begin{tabular}{|cc|cc|}
\hline 2 & 3 & 1 & 4 \\
5 & 7 & 6 & 9 \\
8 & 10 & 11 & 12 \\
15 & 16 & 13 & 14 \\
\hline
\end{tabular}

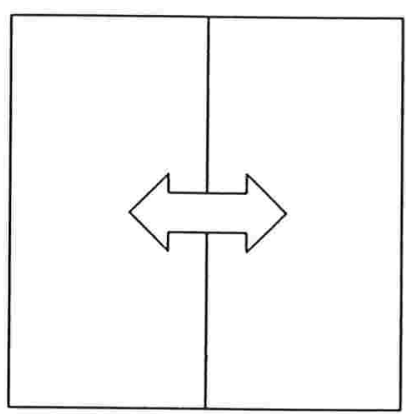

\begin{tabular}{|c|c|c|c|}
\hline 2 & 3 & 1 & 4 \\
5 & 7 & 6 & 9 \\
8 & 10 & 11 & 12 \\
15 & 16 & 13 & 14 \\
\hline
\end{tabular}

\begin{tabular}{|c|c|c|c|}
\hline impar & par & impar & par \\
& & & \\
& & & \\
& & & \\
\hline
\end{tabular}




\begin{tabular}{|cc|cc|}
\hline 2 & 1 & 3 & 4 \\
5 & 6 & 7 & 9 \\
8 & 11 & 10 & 12 \\
15 & 13 & 16 & 14 \\
\hline
\end{tabular}

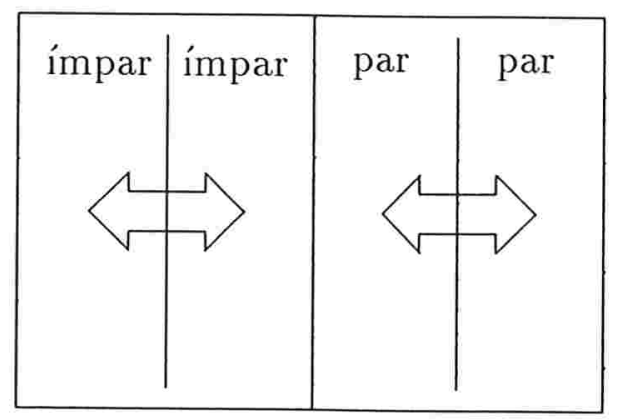

\begin{tabular}{|cc|cc|}
\hline 1 & 2 & 3 & 4 \\
5 & 6 & 7 & 9 \\
8 & 11 & 10 & 12 \\
13 & 15 & 14 & 16 \\
\hline
\end{tabular}

\begin{tabular}{|l|l|}
\hline C & D \\
& \\
\hline & \\
\hline
\end{tabular}

\begin{tabular}{|c|c|}
\hline $1_{3}$ & $2_{4}$ \\
$5_{7}$ & $6_{9}$ \\
$8_{10}$ & $11_{12}$ \\
$13_{14}$ & $15_{16}$ \\
\hline
\end{tabular}

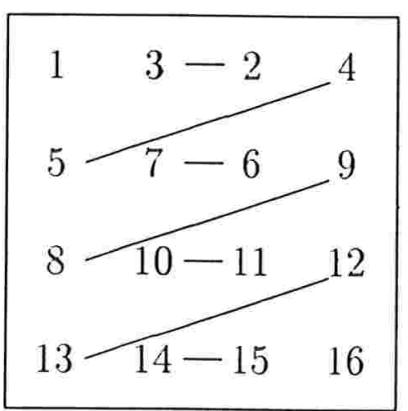


Obtemos finalmente a grade com os elementos ordenados.

\begin{tabular}{|cccc|}
\hline 1 & 2 & 3 & 4 \\
5 & 6 & 7 & 8 \\
9 & 10 & 11 & 12 \\
13 & 14 & 15 & 16 \\
\hline
\end{tabular}

Notamos que os algoritmos recursivos apresentados neste capítulo utilizam uma grade e todas as suas subgrades. Se mapearmos esta grade em um hipercubo utilizando o método do dobramento recursivo, podemos identificar facilmente as suas subgrades em cada passo da recursão. Assim, obtemos sem grande esforço os algoritmos correspondentes para o hipercubo. 


\section{Capítulo 5}

\section{Conclusão}

A imersão de uma rede de interconexão em uma outra é uma questão muito importante no projeto e análise de algoritmos. Através de uma imersão, algoritmos projetados originalmente para uma arquitetura podem ser diretamente mapeados para outra arquitetura.

Iniciamos este trabalho apresentando algumas redes de interconexão mais populares, como árvores binárias, grades, pirâmides, borboletas, entre outras. Em seguida, exibimos os resultados já conhecidos das imersões destas redes em seus respectivos hipercubos ótimos.

Neste trabalho, descrevemos dois métodos que permitem a imersão de um $m$-cubo $r$-ário em um hipercubo de mesmo número de nós com dilatação 1 , o método do dobramento recursivo [HS96, Son94] e o do código de Gray [SSS8].

O método do dobramento recursivo possui uma propriedade adicional não encontrada no método do código de Gray. A disposição dos nós de um hipercubo dada por $T(r, m)$, conforme a seção 3.3.1, possui uma propriedade desejável expressa pelo Corolário 3.3.1: Todos os subcubos, formados pelos nós com os mesmos primeiros $\mathrm{km}$ bits, para $1 \leq k<\log r$, também estão dispostos em $m$-cubos $\left(r / 2^{k}\right)$-ários. Este método possibilita a identificação imediata de todos os subcubos menores de um $m$-cubo $r$-ário mapeado no hipercubo.

O principal objetivo de nossa dissertação foi a apresentação de aplicações concretas que podem tirar vantagem da propriedade citada acima, pois nas publicações anteriores sobre o método do dobramento recursivo não há exemplos que ilustrem a aplicabilidade e utilidade desta propriedade. Mostramos neste trabalho que o método do dobramento recursivo pode ser útil para uma classe de problemas matriciais resolvidos com algoritmos do tipo divisão-e-conquista. Mais especificamente, apresentamos três algoritmos recursivos, para 
os problemas de obtenção da transposta de uma matriz, multiplicação de matrizes e ordenação por intercalação Par-Ímpar, propostos para um $m$-cubo $r$-ário que necessitem de todos os subcubos menores. Estes algoritmos recursivos foram projetados para uma grade (2-cubo $r$-ário) que utilizam todas as suas subgrades. Usando a disposição $T(r, 2)$ fazemos uma imersão da grade no hipercubo. $O$ método de imersão do dobramento recursivo permite identificar todas as subgrades de maneira imediata. Assim, obtemos facilmente o correspondente algoritmo para o hipercubo.

Devemos observar que não estamos sugerindo que estes algoritmos para os problemas específicos sejam bons algoritmos para hipercubos, pois sabemos que existem outros melhores. Entretanto, um dos objetivos da imersão de outras redes de interconexão no hipercubo é o de permitir a utilização de algoritmos originalmente desenvolvidos para estas redes no hipercubo. Isto geralmente implica numa subutilização do hipercubo. Tendo isto em mente, as aplicações apresentadas nesta dissertação ilustram tão somente a aplicabilidade da propriedade do método do dobramento recursivo no aproveitamento de algoritmos propostos para grades no hipercubo. 


\section{Apêndice A}

\section{Tabelas de parâmetros}

Neste apêndice, apresentamos duas tabelas. A primeira tabela mostra algumas das principais redes de interconexão e seus parâmetros de desempenho e a segunda apresenta resultados conhecidos de imersões no hipercubo. 


\begin{tabular}{|c|c|c|c|c|c|c|c|c|c|}
\hline 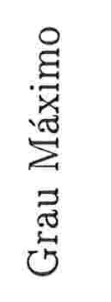 & $\varepsilon$ & 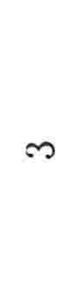 & 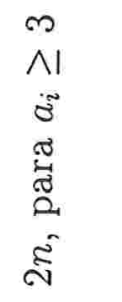 & 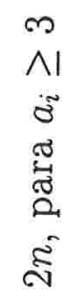 & 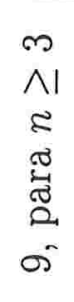 & 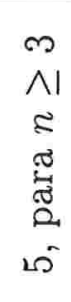 & 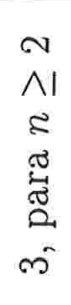 & 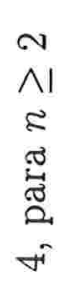 & $\infty$ \\
\hline 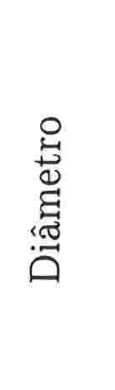 & $\approx$ & हิ & $\begin{array}{l}\vdots \overrightarrow{7} \\
+1 \\
-1 \\
1 \quad \frac{1}{5} \\
8 \\
8\end{array}$ & 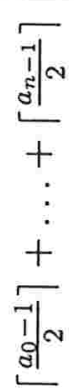 & $\begin{array}{l}\vec{i} \\
1 \\
\tilde{N}\end{array}$ & $\begin{array}{l}\vec{I} \\
\vec{I} \\
\overrightarrow{\mathrm{N}}\end{array}$ & $\tilde{f}$ & $\begin{array}{l}\overrightarrow{\approx I N} \\
+ \\
c\end{array}$ & 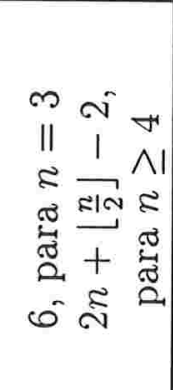 \\
\hline 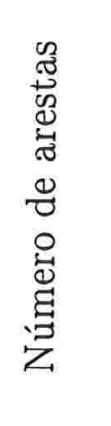 & $\begin{array}{l}\overrightarrow{1} \\
\text { है } \\
\text { है }\end{array}$ & $\begin{array}{c}N \\
1 \\
\not{+} \\
\stackrel{\vec{N}}{N}\end{array}$ & 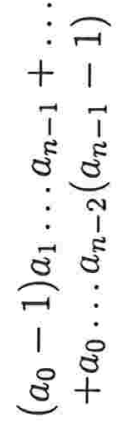 & $\begin{array}{c}\frac{5}{71} \\
1 \\
5 \\
\vdots \\
8 \\
8\end{array}$ & 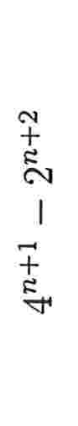 & 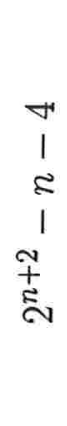 & 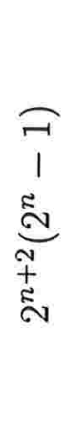 & $\begin{array}{l}\overrightarrow{+} \\
\stackrel{\text { స్ }}{\text { E }}\end{array}$ & $\begin{array}{l}\vec{\jmath} \\
\tilde{\tilde{N}} \\
\tilde{\text { है }}\end{array}$ \\
\hline 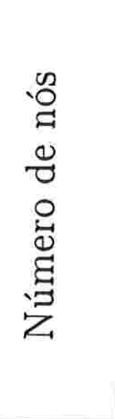 & $\tilde{\overbrace{}}$ & $\begin{array}{c}\overrightarrow{1} \\
\vec{I} \\
\overrightarrow{ \pm} \\
\text { जे }\end{array}$ & $\begin{array}{c}\overrightarrow{1} \\
\text { है } \\
\vdots \\
\overrightarrow{0} \\
8\end{array}$ & $\begin{array}{c}\overrightarrow{1} \\
\text { है } \\
\vdots \\
\vdots \\
\overrightarrow{8} \\
0\end{array}$ & $\begin{array}{l}\underset{7}{1} \\
+1 \\
+ \\
\underset{-1 m}{E}\end{array}$ & $\begin{array}{c}\overrightarrow{1} \\
\overrightarrow{1} \\
\overrightarrow{+} \\
\stackrel{\Xi}{\sigma}\end{array}$ & 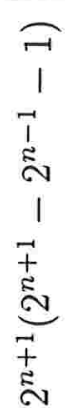 & స్ है & ఓ్ ఓ్ \\
\hline 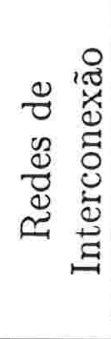 & 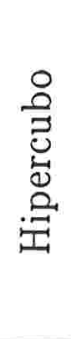 & 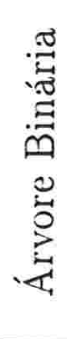 & 莡 & 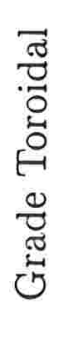 & 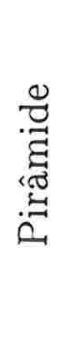 & 竞 & 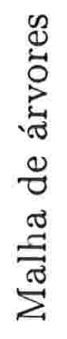 & 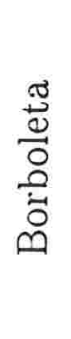 & 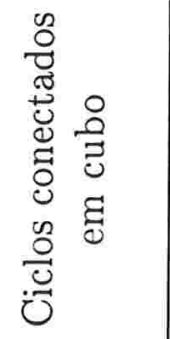 \\
\hline
\end{tabular}

Tabela A.1: Exemplos de redes de interconexão e seus parâmetros de desempenho. 


\begin{tabular}{|c|c|c|}
\hline $\begin{array}{c}\text { Redes de } \\
\text { Interconexão }\end{array}$ & $\begin{array}{l}\text { Hipercubo } \\
\text { Ótimo }\end{array}$ & Dilatação \\
\hline Árvore Binária & $Q(n+1)$ & 2 \\
\hline Grade & $Q\left(\left\lceil\log a_{0}\right\rceil+\ldots+\left\lceil\log a_{n-1}\right\rceil\right)$ & $\begin{array}{c}1, \text { se } \\
\left\lceil\log a_{0}\right\rceil+\ldots+\left\lceil\log a_{n-1}\right\rceil= \\
\left\lceil\log a_{0}+\ldots+\log a_{n-1}\right\rceil\end{array}$ \\
\hline Grade Bidimensional & $Q\left(\left\lfloor\log a_{0}\right\rfloor+\left\lfloor\log a_{1}\right\rfloor+1\right)$ & 2 \\
\hline Pirâmide & $Q(2 n+1)$ & 2 \\
\hline X-Árvore & $Q(n+1)$ & 2 \\
\hline Malha de árvores & $Q(2 n+2)$ & 2 \\
\hline Borboleta & $Q(n+\lceil\log n\rceil)$ & $1+(n \bmod 2)$ \\
\hline $\begin{array}{c}\text { Ciclos conectados } \\
\text { em cubo }\end{array}$ & $Q(n+\lceil\log n\rceil)$ & $1+(n \bmod 2)$ \\
\hline
\end{tabular}

Tabela A.2: Resultados da imersão de algumas redes de interconexão em seus respectivos hipercubos ótimos. 


\section{Bibliografia}

[Bat68] K. E. Batcher. Sorting networks and their applications. In Proceedings, AFIPS Spring Joint Computer Conference, pages 307-314, AFIPS Press, Reston, Virginia, 1968.

[BCLR86] S. Bhatt, F. Chung, T. Leighton, and A. Rosenberg. Optimal simulations of tree machines. In 27th Annual Symposium on Foundations of Computer Science, pages 274-282, Toronto, Ontario, Canada, October 1986. IEEE.

[BI85] S. N. Bhatt and I. C. F. Ipsen. How to embed trees in hypercubes. Technical Report YaleU/DCS/RR-443, Departament of Computer Science, Yale University, 1985.

[BM76] J. A. Bondy and U.S. R. Murty. Graph theory with applications The Macmillan Press, Ltd., 1976.

[BS86] J. Brandenburg and D. Scott. Embeddings of communication trees and grids into hypercubes. iPSC Tech. Report, Intel, Number 1, 1986.

[Cha88] M. Y. Chan. Dilation 2-embedding of grids into hypercubes. In Proceedings of 1988 International Conference on Parallel Processing. Algorithms and Applications, pages 295-298, August 1988.

[CC88] M. Y. Chan and F. Y. L. Chin. On embedding rectangular grids in hypercubes. IEEE Transactions on Computers, 37(10):1285-1288, October 1988.

[CC93] M. Y. Chan and F. Y. L. Chin. A parallel algorithm for an efficient mapping of grids in hypercubes. IEEE Transactions on Parallel and Distributed Systems,4(8):933-946, August 1993.

[FHL97] I. Fris ${ }^{a}$, I. Havel and P. Liebl. The diameter of the cube-connected cycles. Information Processing Letters, 61(3):157-160, 1997.

[GHR90] D. S. Greenberg, L. S. Heath, and A. L. Rosenberg. Optimal embeddings of butterfly-like graphs in the hypercube. Mathematical Systems Theory, 23(1):61-77, 1990. 
[Hav84] I. Havel. On Hamiltonian circuits and spanning trees of hypercubes. Casopis Pest. Mat., 109(2):135-152, 1984.

[HS96] M. Hamdi and S. W. Song. On Embedding Various Networks into the Hypercube Using Matrix Transformations. 10th International Parallel Processing Symposium, IEEE Computer Society, pages 650-654, April 15-19, 1996.

[KGGK94] V. Kumar, A. Grama, A. Gupta, and G. Karypis. Introduction to Parallel Computing - Design and Analisys of Algorithms The Benjamin/Cummings Publishing Company, Inc., 1994.

[Knu73] D. E. Knuth. The art of computer programming, Volume 3, Sorting and searching. Addison Wesley, Reading, MA, 1973.

[Lei92] F. T. Leighton. Introduction to Parallel Algorithms and Architectures. Morgan Kaufmann, San Mateo, CA, 1992.

[LW90] T. H. Lai and W. White. Mapping pyramid algorithms into hypercubes. Journal of Parallel and Distributed Computing, 9(1):42-54, May, 1990.

[MLS88] F. Makedon, T. Leighton, and I. H. Sudborough. Simulating pyramid machines with a hypercube. Manuscript, Computer Science Program, University of Texas at Dallas, 1988.

[MS88a] B. Monien and I. H. Sudborough. Simulating binary trees on hypercubes. In Proceedings Third Aegan Workshop on Computing. Lecture Notes in Computer Science, volume 319, pages 170-180, 1988.

[MS88b] B. Monien and I. H. Sudborough. Comparing interconnection networks. In Mathematical Foundations of Computer Science. Lecture Notes in Computer Science, volume 324, pages 138-153, 1988.

[Neb74] L. Nebesky. On cubes and dichotomic trees. Casopis Pest. Mat., 1974.

[San92] C. A. A. Sanches. Novos algoritmos SIMD para multiplicação de matrizes no hipercubo. Dissertação de Mestrado, Instituto de Matemática e Estatística da Universidade de São Paulo, 1992.

[Son94] S. W. Song. Embedding of meshes on the hypercube by recursive folding. IEEE/USP International Workshop on High Performance Computing, pages 83-95, March 1994.

[SSS8] Y. Saad and M. H. Schultz. Topological properties of hypercubes. IEEE Transactions on Computers, 37(7):867-872, July 1988.

[Ull83] J. D. Ullman. Computational Aspects of VLSI. Computer Science Press, Inc., 1983. 